NBER WORKING PAPER SERIES

\title{
BUNDLING AMONG RIVALS: A CASE OF PHARMACEUTICAL COCKTAILS
}

\author{
Claudio Lucarelli \\ Sean Nicholson \\ Minjae Song \\ Working Paper 16321 \\ http://www.nber.org/papers/w16321 \\ NATIONAL BUREAU OF ECONOMIC RESEARCH \\ 1050 Massachusetts Avenue \\ Cambridge, MA 02138 \\ August 2010
}

We have benefited from discussions with Yongmin Chen, Joshua Lustig, Jae Nahm, Michael Raith, Michael Riordan, Michael Waldman, and comments by seminar participants at Columbia University, the Cowles Foundation, the Federal Trade Commission, the 2009 IIOC, Korea University, SKK University, the University of Rochester and the University of Wisconsin-Madison. All errors are ours. The views expressed herein are those of the authors and do not necessarily reflect the views of the National Bureau of Economic Research.

NBER working papers are circulated for discussion and comment purposes. They have not been peerreviewed or been subject to the review by the NBER Board of Directors that accompanies official NBER publications.

(C) 2010 by Claudio Lucarelli, Sean Nicholson, and Minjae Song. All rights reserved. Short sections of text, not to exceed two paragraphs, may be quoted without explicit permission provided that full credit, including $\odot$ notice, is given to the source. 
Bundling Among Rivals: A Case of Pharmaceutical Cocktails

Claudio Lucarelli, Sean Nicholson, and Minjae Song

NBER Working Paper No. 16321

August 2010

JEL No. I11,L1,L11

\begin{abstract}
$\underline{\text { ABSTRACT }}$
We empirically analyze the welfare effects of cross-firm bundling in the pharmaceutical industry. Physicians often treat patients with "cocktail" regimens that combine two or more drugs. Firms cannot price discriminate because each drug is produced by a different firm and a physician creates the bundle in her office from the component drugs. We show that a less competitive equilibrium arises with cocktail products because firms can internalize partially the externality their pricing decisions impose on competitors. The incremental profits from creating a bundle are sometimes as large as the incremental profits from a merger of the same two firms.

\author{
Claudio Lucarelli \\ Assistant Professor \\ Minjae Song \\ Department of Policy Analysis \\ Assistant Professor \\ and Management \\ Simon Graduate School of Business \\ Cornell University \\ University of Rochester \\ MVR Hall \\ Ithaca, NY 14853-4401 \\ Rochester, NY 14627-0100 \\ c1443@cornell.edu \\ minjae.song@simon.rochester.edu \\ Sean Nicholson \\ Associate Professor \\ Department of Policy Analysis and Management \\ Cornell University \\ 123 Martha Van Rensselaer Hall \\ Ithaca, NY 14853 \\ and NBER \\ sn243@cornell.edu
}




\section{Introduction}

In the pharmaceutical market patients often take a combination of two or more drugs in order to improve the efficacy of treating a disease or alleviate side effects. Most HIV/AIDS patients, for example, receive a "cocktail" regimen, such as efavirenz, lamivudine, and zidovudine. Three of the six new cholesterol-reducing drugs entering phase 3 clinical trials in 2007 were combinations of drugs that had already been approved as stand-alone products to treat the disease (BlumeKohout and Sood, 2008). In 2008, thirty-one percent of U.S. colorectal cancer patients receiving chemotherapy treatment were administered cocktail regimens. A pharmaceutical cocktail must be approved by the Food and Drug Administration (FDA) by demonstrating superior efficacy, fewer side effects, or greater convenience relative to existing drugs, even if the cocktail is a combination of already-approved drugs. Thus, cocktails compete with stand-alone regimens.

In this paper we analyze empirically the welfare effects of cross-firm bundling for pharmaceutical treatment of cancer patients where each cocktail consists of drugs made by different firms, and each drug is also offered as a stand-alone product. In this market a firm is constrained to set the same price (i.e., a price per milligram of active ingredient) for both its stand-alone product as well as its component of a cocktail product. This pricing constraint exists because oncologists purchase the component drugs from different manufacturers and then infuse the regimen into a patient in an office or hospital clinic. ${ }^{1}$ This is an example of mixed bundling in an oligopoly market, where there is demand for a bundle of products due to their complementarity but firms cannot price discriminate.

Firms often bundle or tie their own products for various reasons, and there is a substantial economic literature analyzing this practice. Bundling may allow a firm to engage in price discrimination (McAfee and Whinston, 1989), to leverage monopoly power in one market by foreclosing sales and discouraging entry in another market (Whinston, 1990; Chen, 1997; Carlton and Waldman, 2002; Nalebuff, 2004), or alter a pricing game among oligopolists even when entry is not deterred or no firms exit (Carlton, Gans, and Waldman, 2007). However, little is known about price changes when a firm's product is bundled with those of its rival, and welfare effects of this practice.

\footnotetext{
${ }^{1}$ Most HIV/AIDS patients, on the other hand, take a single pill that contains two or more separate drugs, which allows firms to price discriminate.
} 
Firms entering the oncology market often test their experimental drug in combination with a drug that is already approved. The entering firm can purchase the approved product without the permission of the incumbent firm, and administer the two drugs together in a clinical trial. ${ }^{2}$ The fact that an entering firm bears the cost of clinical trials indicates that it expects positive profit. The cocktail's impact on incumbents, however, is not clear a priori. Patients may prefer having cocktail regimens because they provide more options for treatment, but if prices increase substantially as a result, patients may be worse off with cocktails. Cocktail regimens allow firms to internalize partially the externalities their pricing strategies impose on competitors. Cocktails also steal market share from existing regimens. If the former effect is larger than the latter, cocktails render the market less competitive; if the latter effect is larger, cocktails increase competition.

We focus on the market for colorectal cancer chemotherapy drugs. We first estimate a demand system at the regimen level using data on regimen prices, market shares, and attributes. ${ }^{3}$ Regimens, which can be a single drug or a cocktail of two or more drugs, are well defined and standardized. Organizations such as the National Comprehensive Cancer Network (NCCN) recommend the amount of each drug that oncologists should use in each regimen, based on the dosages used in clinical trials or in actual practice. A regimen price is a function of the price and quantity (or dose) of each component drug used in the regimen. A cocktail regimen's price is thus affected by prices of all drugs used in the regimen, and a firm whose drug is used in a cocktail regimen must set a single drug price to maximize profit across its stand-alone and cocktail products.

Market share is defined as the proportion of chemotherapy patients treated with a particular regimen. Data from randomized clinical trials provide information on attributes such as regimen efficacy (e.g., median number of months patients survived in the clinical trial) and side effects (e.g., the percent of patients in the clinical trial who experienced abdominal pain).

The demand estimates and a profit maximization condition allow us to recover the marginal cost of each drug. We analyze the economic effects of cocktails by performing a series of counter-

\footnotetext{
${ }^{2}$ Rather than modeling a firm's decision regarding whether and how to combine its product with other firms' products, we take existing product combinations as given. Scott Morton (1999) is the only paper we are aware of that models explicitly a pharmaceutical firm's decison of whether to enter a market, and she focuses on the subsequent entry of generic firms rather than the initial decision by the innovating firm. She finds that generic pharmaceutical firms tend to enter markets that have supply and demand characteristics similar to the firm's portfolio of products.

${ }^{3}$ Our empirical approach allows us to study bundled pricing in an unrestrictive way. The existing bundling literature assumes either that the utility of consuming a bundle is the sum of utilities of each product (independent products) or that it is less than the sum (substitutes). Instead, we use data to measure directly the utility of each product.
} 
factual exercises. First, we remove cocktail regimens one at a time and compute new equilibrium prices. One underlying assumption is that drug-level marginal costs and patients' preference regarding efficacy and side effects do not change when a regimen is removed; regimen-level own- and cross-price elasticities, however, do change. We find that profits of all firms involved in that cocktail decrease and consumer surplus increases when a cocktail is removed. Cocktail regimens increase profits for an entrant as well as the incumbent, but harm consumers. This occurs because cocktail regimens result in high drug prices; the effect of internalizing pricing externalities dominates the business stealing effect in our application.

In the second counterfactual we compare the market with cocktails to markets with hypothetical mergers between firms that contribute to a cocktail. This allows us to assess how collusive the market has become with cocktail regimens. We consider two merger scenarios. In the first scenario we remove one cocktail regimen and allow the two participating firms to merge instead. We find that firms can earn higher profits from having a cocktail regimen than from the merger. In the second merger scenario we allow a pair of firms to merge while maintaining their cocktail regimen. The merging firm has an incentive to increase prices to exploit its market power, but at the same time it also has an incentive to lower prices to exploit a cocktail regimen's complementarity. We find that some hypothetical mergers result in higher prices and others in lower prices, but the merger never increases profits substantially. Specifically, a firm's profit never increases by more than 12 percent and in one case the merging firm's profit actually falls. These results indicate that cocktails facilitate almost as much collusion as mergers.

In the third counterfactual we allow a firm to set two separate drug prices, one for its stand-alone regimen and the other for its component drug in a cocktail regimen. This is equivalent to a case where a firm has two separate drugs, one used by itself and the other in a cocktail regimen. Setting two prices introduces a new strategic incentive that we observe in other sectors of the pharmaceutical market. In the early 2000s Abbott launched Kaletra, a drug for treating HIV/AIDS. At the time Abbott was already selling Norvir, which was used in a cocktail regimen to help boost the performance of its competitor's drug. Shortly after the launch of Kaletra, Abbott increased Norvir's price four-fold while pricing Kaletra more competitively, presumably to drive customers from the cocktail regimen to its new stand-alone regimen. Although we do not observe a similar situation in the colorectal drug market, we use this exercise as an "out-of-sample" validation 
test for our static Nash pricing assumption. We find similar pricing behaviors in our counterfactual: firms set the price of the cocktail component higher than the stand-alone drug when allowed this flexibility.

In addition to the bundling literature, this paper is also related to the literature on the determinants of pharmaceutical prices. Saha et. al. (2006), Frank and Salkever (1997), and Grabowski and Vernon (1992) show how prices fall as generic firms enter following the expiration of a patent; Duggan and Scott Morton (2006) examine how Medicaid policy affects pharmaceutical prices in the non-Medicaid market; and Duggan and Scott Morton (2010), Lichtenbeg and Sun (2007), Ketcham and Simon (2008), Yin et. al. (2008), and Lakdawalla and Yin (2010) demonstrate that the expansion of prescription drug insurance to Medicare beneficiaries caused pharmaceutical prices to fall. Unlike the studies mentioned above, we use a demand model to analyze the welfare effects of firms' pricing decisions, focusing on a sector where all chemotherapy options are substitutes for one another. The model allows us to account explicitly for both the demand effects and the competition effects of cocktail products.

In Section 2 we present an overview of colorectal cancer treatment and we describe the data in Section 3. We present the model in Section 4 and simple numerical examples in Section 5 where two firms each have a single stand-alone regimen and each contribute their drug to a third cocktail regimen. Results from the demand estimation and counterfactual exercises are presented in Section 6 and Section 7, respectively. We conclude in Section 8.

\section{Overview of Colorectal Cancer}

Colorectal cancer is the fourth most common cancer based on the number of newly-diagnosed patients, after breast, prostate, and lung cancers. About one in 20 people born today is expected to be diagnosed with colorectal cancer over their lifetime. The disease is treatable if it is detected before it metastasizes, or spreads, to other areas of the body. Between 1999 and 2006, colorectal cancer patients had a 65 percent chance of surviving for five years and a 58 percent chance of surviving for 10 years (National Cancer Institute). The probability a patient will survive for five years ranges from 90 percent for those diagnosed with Stage I cancer to 12 percent for those 
diagnosed with Stage IV (or metastatic) cancer. ${ }^{4}$

The way a colorectal cancer patient is treated depends on the stage of the tumor at diagnosis. Most patients with a Stage I, II, or III tumor will have the tumor removed surgically (i.e., resected). The NCCN recommends that patients with Stage III disease receive six months of chemotherapy following the resection; they do not recommend chemotherapy for Stage I patients; and they encourage Stage II patients to discuss the benefits and costs of with their oncologist before deciding. The majority of patients diagnosed with Stage IV disease have an unresectable tumor. Some of these patients receive chemotherapy to shrink the tumor such that it can be resected, and many receive chemotherapy without prior surgical treatment. Our demand model examines patients' chemotherapy treatments choices once they have decided to receive chemotherapy; we assume patients have already decided whether or not to receive surgery prior to chemotherapy treatment.

Five major pharmaceutical firms produced a patent-protected (or branded) colorectal cancer drug during our study period: Pfizer (which produced irinotecan), Roche (capecitabine), Sanofi (oxaliplatin), ImClone (cetuximab), and Genentech (bevacizumab). There are 12 major treatment regimens, half of which are cocktail regimens, composed of two or more branded drugs, and half consist of a single branded drug. In one cocktail regimen, Roche's capecitabine is combined with Pfizer's irinotecan. In another capecitabine is combined with Sanofi's oxaliplatin. Genentech's bevacizumab is combined separately with oxaliplatin, irinotecan, and oxaliplaitin and capecitabine to create three distinct cocktail regimens. Finally, ImClone's cetuximab is combined with Pfizer's irinotecan. ${ }^{5}$

Three of the remaining six regimens are individual drugs used in the cocktail regimens mentioned above, but in different dosages. The other non-cocktail regimen are fluourouracil combined with leucovorin $(5 \mathrm{FU} / \mathrm{LV})$, both of which are generic drugs; Pfizer's irinotecan combined with 5FU/LV; and Sanofi's oxaliplatin combined with 5FU/LV. We take the generic drug's price as given and assume they are priced at marginal cost, not the result of firms' strategic pricing. We therefore treat the last two regimens described above as being stand-alone regimens. The appendix

\footnotetext{
${ }^{4}$ Cancers are classified into four stages, with higher numbers indicating that the cancer has spread to the lymph nodes (Stage III) or beyond its initial location (Stage IV).

${ }^{5}$ Some of the cocktail regimens also include generic drugs such as fluorouracil and leucovorin, whose patents have expired and are now produced by many firms.
} 
provides a complete description of the recommended dosage of the 12 regimens for which we have complete data.

The National Comprehensive Cancer Network (NCCN) divides colorectal cancer chemotherapy regimens into two groups. For early-stage patients who cannot tolerate intensive therapy, it recommends 5FU/LV (the generic regimen), Roche's stand-alone regimen, or the Pfizer-Roche cocktail regimen. The other regimens are recommended for those who can tolerate the possible side effects of intensive therapy. The NCCN also provides chemotherapy guidelines for patients whose cancer progresses in spite of the first chemotherapy treatment. For example, if the Roche and Sanofi cocktail regimen was selected for initial therapy, the NCCN recommends the Pfizer and ImClone cocktail for second-line chemotherapy treatment. In Section 4 we use these guidelines to define the nests for a nested logit demand model.

Most oncology drugs are infused into a patient intravenously in a physician's office or an outpatient hospital clinic by a nurse under a physician's supervision. Unlike drugs that are distrib-

uted through pharmacies, physicians (and some hospitals on behalf of their physicians) purchase oncology drugs from wholesalers or distributors (who have previously purchased the drugs from the manufacturers), store the drugs, and administer them as needed to their patients. Physicians then bill the patient's insurance company for an administration fee and the cost of the drug. In our model we assume physicians are agents for their patients; we explain the details of the imperfect agency in Section 4.

Because each drug is sold separately to physicians who then combine them (when relevant) into a cocktail regimen, the only variable a firm controls is the price of its own drug. This price, in turn, affects the demand and profits of all cocktail regimens in which the drug appears. We explicitly account for this impact in our supply-side (pricing) model in Section 4.

\section{Data}

We use several data sources to collect four types of information: drug prices, regimen market shares, the quantity/dose of each drug typically used in a regimen, and regimen attributes from clinical trials (e.g., the median number of months patients survived when taking the regimen in a phase 3 clinical trial). IMS Health collects information on the sales in dollars and the quantity of drugs 
purchased by 10 different types of customers (e.g., hospitals, physician offices, retail pharmacies) from wholesalers in each quarter from 1993 through the third quarter of 2005. Prices and quantities are reported separately by National Drug Classification (NDC) code, which are unique for each firmproduct-strength/dosage-package size. We calculate the average price paid per milligram of active ingredient of a drug across the different NDC codes for a particular drug. IMS Health reports the invoice price a customer actually pays to a wholesaler, not the average wholesale price (AWP) that is set by a manufacturer and often differs substantially from the true transaction price.

The price we calculate does not include any discounts or rebates a customer may receive from a manufacturer after purchasing the product from the wholesaler. Based on interviews with oncologists and an analysis reported in Lucarelli, Nicholson, and Town (2010), we do not believe that manufacturers offered substantial rebates during this period. ${ }^{6}$ Although we have information on 10 different types of customers, we focus on the prices paid by the two largest customers hospitals and physician offices -because most colon cancer chemotherapy drugs are infused in a physician's office or hospital clinic. ${ }^{7}$

We compute the price of each regimen for a representative patient who has a surface area of 1.7 meters squared (Jacobson and Newhouse, 2006), weighs 80 kilograms, and is treated for 12 weeks. Regimen prices are derived by multiplying the average price per milligram of active ingredient in a quarter by the recommended dosage of each drug in the regimen over a 12-week period. ${ }^{8}$ The NCCN reports the typical amount of active ingredient used by physicians for the major regimens. ${ }^{9}$ Dosage information is reported in the appendix. For example, the standard dosage schedule for oxaliplatin $+5 \mathrm{FU} / \mathrm{LV}$, the regimen with the second largest market share in 2005, is 85 milligrams (mg) of oxaliplatin per meter squared of a patient's surface area infused on the first day of treatment, followed by a 1,000 mg infusion of fluourouracil (5FU) per meter squared of surface area on the first and second treatment days, and a $200 \mathrm{mg}$ infusion of leucovorin (LV) per meter squared on the first and second treatment days. This process is repeated every two weeks.

\footnotetext{
${ }^{6}$ For the five patent-protected colorectal cancer drugs in our study, Lucarelli, Nicholson, and Town (2010) compared prices that include discounts and rebates to the IMS prices that we use in this paper. They found that prices from the two data sources were within two to four percent of one another, which is consistent with no or small rebates/discounts.

${ }^{7}$ Based on data from IMS Health, $59 \%$ of colorectal cancer drugs in the third quarter of 2005 were purchased by physician offices and $28 \%$ by hospitals. The remainder was purchased by retail and mail order pharmacies, health maintenance organizations, and long-term care facilities.

${ }^{8}$ The regimens are priced using price data for the contemporaneous quarter only.

${ }^{9}$ We supplement this where necessary with dosage information from drug package inserts, conference abstracts, and journal articles.
} 
The IMS Health data contain information on market share by drug, but not market share for combinations of drugs (regimens). We rely, therefore, on two different sources for regimen-specific market shares, where market share is defined as the proportion of colorectal cancer chemotherapy patients treated with a particular regimen. IntrinsiQ collects monthly data from its oncology clients on the types of chemotherapy drugs administered to patients. Based on these data, we derive monthly market shares for each regimen between January 2002 and September 2005.

Since IntrinsiQ's data only go back to 2002, we rely on the Surveillance Epidemiology and End Results (SEER) data set for market shares for the 1993 to 2001 period. SEER tracks the health and treatment of cancer patients over the age of 64 in states and cities covering 26 percent of the United States population. ${ }^{10}$ Based on Medicare claims data available in SEER, we calculate each colorectal cancer regimen's market share in each quarter. ${ }^{11}$

In order to standardize market shares between the pre- and post-2002 periods, we take advantage of the fact that the two data sets overlap for the four quarters of 2002. We apply a regimen-specific factor to adjust the pre-2002 market shares based on the ratio of total (from IntrinsiQ) to Medicare-only (from SEER) market shares for the four quarters of 2002. The underlying assumption in this adjustment is that the proportion of total patients represented by Medicare does not vary over time.

All regimens we include in the sample contain drugs that were approved by the FDA for colorectal cancer and had a market share greater than one percent at the end of the sample period. The outside option includes off-label drugs, regimens with less than one percent market share at the end of the sample period, and regimens with missing attribute data. ${ }^{12}$

We plot market shares for the 12 regimens in the sample and the outside option in Figure 1. Between 1993 and 1996, about 95 percent of colorectal cancer patients were treated with 5FU/LV, a generic regimen, with the remainder treated with off-label drugs or regimens with small market share. In 1996 irinotecan was approved by the FDA for treating colorectal cancer, and over the next several years the market share of irinotecan and irinotecan combined with 5FU/LV grew at

\footnotetext{
${ }^{10}$ SEER contains data on the incidence rate of cancer among the non-elderly, but only has medical claims available for Medicare patients.

${ }^{11}$ According to IntrinsiQ's data, approximately 48 percent of all colorectal cancer chemotherapy patients were 65 years or older in October 2003.

${ }^{12}$ Off-label use occurs when a physician treats a colorectal cancer patient with a drug that has not been approved by the FDA explicitly for colorectal cancer.
} 
the expense of $5 \mathrm{FU} / \mathrm{LV} .{ }^{13}$ Capecitabine, a tablet that produces the same chemical response as $5 \mathrm{FU} / \mathrm{LV}$, was approved for treatment of colorectal cancer in April 2001 and was administered as a stand-alone therapy or combined with irinotecan. Besides capecitabine, all other drugs for treating colorectal cancer in our sample are delivered intravenously (i.e., by IV) under the supervision of a physician or nurse.

Oxaliplatin was introduced in August 2002, followed by cetuximab and bevacizumab in February 2004. By the third quarter of 2005, two of the regimens created by these three new drugs (oxaliplatin $+5 \mathrm{FU} / \mathrm{LV}$ and bevacizumab + oxaliplatin $+5 \mathrm{FU} / \mathrm{LV})$ surpassed the market share of $5 \mathrm{FU} / \mathrm{LV}$, whose share had fallen to about 14 percent. $^{14}$

We obtain most of the attribute information from the FDA-approved package inserts that accompany each drug. These inserts describe the performance of the drug/regimen in phase 3 clinical trials, including the number and types of patients enrolled in the trials, the health outcomes for patients in the treatment and control groups, and the side effects experienced by these patients. Often there are multiple observations for a regimen, either because a manufacturer conducted separate trials of the same regimen, or because a regimen may have been used for the treatment group in one clinical trial and the control group in a subsequent trial. In these cases we calculate the mean attributes across the separate observations. Where necessary, we supplement the package insert information with abstracts presented at oncology conferences and journal articles.

We summarize the attribute information in Table 1, taking a weighted (by market share) average across regimens in each quarter and then averaging across quarters for each year. The efficacy and side effect attributes are time invariant while price can change each quarter. We record three measures of a regimen's efficacy: the median number of months patients survive after initiating therapy (Survival Months); the percentage of patients who experience a complete or partial reduction in the size of their tumor (Response Rate); and the mean number of months (across patients in the trial) before the cancer advanced to a more serious state (Time to Progression).

We also record the percentage of patients in phase 3 trials who experienced either a grade 3 or a grade 4 side effect for five separate conditions: abdominal pain, diarrhea, nausea, vomiting,

\footnotetext{
${ }^{13}$ Because it takes Medicare a while to code new drugs into their proper NDC code, a new drug will appear in the outside option for several quarters.

${ }^{14}$ Drugs have brand names in addition to the generic names that we provide in the text. The brand names of the five patent-protected drugs are as follows: Camptosar (irinotecan), Xeloda (capecitabine), Eloxatin (oxaliplatin), Avastin (bevacizumab), and Erbitux (cetuximab).
} 
and neutropenia. Although many more side effects are recorded for most regimens, these five were consistently recorded across the 12 regimens in the sample. Side effects are classified on a 1 to 4 scale, with grade 4 being the most severe. Higher values for the side effect attributes should be associated with worse health outcomes although regimens that are relatively toxic are likely to be both more effective and have more severe side effects.

This table demonstrates that there was a large price increase in 1998. The average regimen price for a 12 -week treatment cycle increased from about $\$ 50$ to over $\$ 300$. This jump is due to the introduction of Pfizer's irinotecan. Since then the average price continued to rise with significant jumps in 2001 when Roche's capecitabine was introduced, and in 2004 when bevacizumab and cetuximab were launched. ${ }^{15}$ New regimens tend to be more efficacious than the existing regimens, with side effect profiles that are sometimes more and sometimes less severe than earlier regimens (Lucarelli and Nicholson, 2008).

\section{Model}

\subsection{Supply}

We assume that firms play a static Nash-Bertrand game with differentiated products. Because drugs in our data set are protected by patents, the firms have considerable market power. However, physicians have multiple treatment alternatives, which puts the firms in an oligopolistic competitive environment. The price hike by Abbott in the AIDS drug market mentioned earlier provides evidence that price is a crucial strategic variable in the pharmaceutical market. In the third counterfactual exercise we show that our static Nash pricing is consistent with the AIDS market case.

The prices of individual drugs do not show any common time trend consistent with dynamic pricing, such as a below-marginal-cost pricing or intertemporal price discrimination. For example, the price of irinotecan, the first patented colorectal cancer drug approved in 30 years, increased steadily from $\$ 4.12$ per milligram in 1998 to $\$ 6.40$ in 2003 , about a $10 \%$ increase annually, and then dropped below five dollars in 2004 when ImClone and Genentech introduced new drugs. The price of oxaliplatin, introduced in 2002 , was stable around $\$ 16$ per milligram for two years and then

\footnotetext{
${ }^{15}$ The price jump in 2000 is due to a market share increase of irinotecan $+5 \mathrm{FU} / \mathrm{LV}$.
} 
dropped about 50 cents after 2004 .

Nevertheless, price setting may not fully describe pharmaceutical firms' strategic behavior. Marketing to physicians (i.e., detailing) is the most important non-price action. We do not observe detailing activity and do not attempt to include it in the model. We also do not explicitly model decisions by some pharmaceutical firms to provide a rebate to certain physicians if their purchased volume exceeds a certain threshold for the quarter or year. We are not aware of any study that examines how physicians react to rebates, presumably because firms do not disclose rebates. And as mentioned above, discounts/rebates in the colorectal chemotherapy market appear to be small. Although these features are not considered in the supply side model, we introduce a shock in the demand model to capture physicians' reaction to such supply-side decisions.

Let $p_{f}$ be the price firm $f$ charges for its drug/product. Consistent with our data, we assume that each firm produces only one drug, and therefore, $p_{f}$ is the only endogenous variable in the firm's optimization problem. We denote $m c_{f}$ as the marginal cost for firm $f$, and $q_{f}(p)$ the quantity produced by firm $f$. Profits for firm $f$ are

$$
\pi_{f}=\left(p_{f}-m c_{f}\right) q_{f}(p)
$$

where $q_{f}(p)$ is obtained by aggregating quantities across the regimens in which the firm participates. Formally, if firm $f$ participates in $R_{f}$ regimens, and $r=1, \ldots, R_{f}$, then $q_{f}(p)$ can be written as

$$
q_{f}(p)=\left(\sum_{r=1}^{R_{f}} s_{r}(p) q_{r f}\right) M
$$

where $s_{r}(p)$ is the share of patients treated with regimen $r, q_{r f}$ is the dosage of the drug produced by firm $f$ used in regimen $r$, and $M$ is the market size. $p_{k}^{R}$, the price of regimen $k$, is determined by $p_{f}$ and $q_{r f}$. For example, if regimen 1 is firm 1's stand-alone regimen, $p_{1}^{R}=q_{11} p_{1}$; if regimen 3 is a cocktail regimen, comprised of drugs from firm 1 and firm $2, p_{3}^{R}=q_{31} p_{1}+q_{32} p_{2}$.

The equilibrium conditions can then be written as

$$
\frac{\partial \pi_{f}}{\partial p_{f}}=\sum_{r=1}^{R_{f}} s_{r}(p) q_{r f}+\left(p_{f}-m c_{f}\right) \sum_{k=1}^{R_{f}} \sum_{r=1}^{R_{f}} \frac{\partial s_{r}(p)}{\partial p_{k}^{R}} \frac{\partial p_{k}^{R}}{\partial p_{f}} q_{r f}=0
$$


Equation (1) shows that a firm will take into account the effect of its drug price on the overall price of each regimen $\left(\partial p_{k}^{R} / \partial p_{f}\right)$, and how changes in regimen prices impact the market shares of all regimens in which a drug participates $\left(\partial s_{r}(p) / \partial p_{k}^{R}\right)$. The former effect is determined by the quantity of a drug used in a recommended regimen "recipe;" the latter effect is determined by the regimen's price elasticity of demand, which we estimate using regimen-level data. We can recover the marginal costs of each drug by re-writing equation (1) for these costs.

Equation (1) highlights that an analytical analysis is not straightforward. Consider the simplest case where firm 1 and firm 2 each sell a stand-alone regimen and there is one cocktail regimen that combines the two firms' drugs. If all three regimens are substitutes for one another, the profit-maximizing first order condition for firm 1 becomes

$$
\frac{\partial \pi_{1}}{\partial p_{1}}=\left(s_{1}(p) q_{11}+s_{3}(p) q_{31}\right)+\left(p_{1}-m c_{1}\right)\left(\frac{\partial s_{1}}{\partial p_{1}^{R}} \frac{\partial p_{1}^{R}}{\partial p_{1}} q_{11}+\frac{\partial s_{1}}{\partial p_{3}^{R}} \frac{\partial p_{3}^{R}}{\partial p_{1}} q_{11}+\frac{\partial s_{3}}{\partial p_{3}^{R}} \frac{\partial p_{3}^{R}}{\partial p_{1}} q_{31}+\frac{\partial s_{3}}{\partial p_{1}^{R}} \frac{\partial p_{1}^{R}}{\partial p_{1}} q_{31}\right)=0
$$

Note that while $\partial p_{k}^{R} / \partial p_{f}$ is fixed by the recommended recipe (which was chosen years earlier when structuring the clinical trial), $\partial s_{r} / \partial p_{k}^{R}$ is a function of price unless one assumes a constant elasticity demand. We rely, therefore, on numerical and empirical analyses to study the economic implications of cocktail regimens.

\subsection{Demand}

We obtain our demand system by aggregating over a discrete choice model of physician behavior. Following the Lancasterian tradition, products are assumed to be bundles of attributes, and preferences are represented as the utility derived from those attributes. A physician may choose a highly effective regimen if a patient can tolerate side effects, or she may choose a less effective regimen with more bearable side effects. We also include price as an attribute. It is not obvious physicians pay attention to price because of health insurance. However, most Medicare patients pay about $20 \%$ of the treatment cost out of their pocket, most private insurance plans require patient cost sharing, and private plans often have a lifetime maximum coverage limit. We also allow physicians to observe regimen-specific attributes beyond those we observe in the clinical trials, i.e., attributes that physicians observe but we do not. 
Regimen attributes, no matter how many we control for, are not adequate to describe physicians' choices fully. Other factors such as patient conditions, detailing activities, and rebates affect treatment choices as well. Because of data limitations, we summarize all these factors with an idiosyncratic shock. We assume a physician draws an i.i.d. shock from the Type I Extreme Value distribution every time she makes a choice, which makes our model a so-called logit demand model. Thus, a physician choice is a probabilistic event, with regimen attributes determining the probability.

The indirect utility of physician $i$ over regimens $j \in\left\{0, \ldots, J_{t}\right\}$ at time (market) $t$ is characterized as

$$
u_{i j t}=-\alpha p_{j t}+\beta x_{j}+\xi_{t}+\Delta \xi_{j t}+\varepsilon_{i j t}
$$

where $p_{j t}$ is the price of regimen $j$ at time $t, x_{j}$ are observable regimen attributes such as efficacy and side effects, $\xi_{t}$ is the mean of unobserved attributes for each period, and $\Delta \xi_{j t}$ is the regimen specific deviation from $\xi_{t} \cdot \varepsilon_{i j t}$ represents the idiosyncratic shock from Type I Extreme Value distribution following McFadden (1981) and Berry (1994).

We estimate $\xi_{t}$ using quarterly indicator variables. $\Delta \xi_{j t}$, which represents demand shocks or regimen attributes that physicians observe but we do not, is likely to be correlated with price. That is, price is endogenous as in most demand models. All terms other than $\varepsilon_{i j t}$ represent patient utility (e.g., patient co-payments, observed and unobserved attributes of the treatment); $\varepsilon_{i j t}$ captures any unobserved elements that affect a physician's choice independent of patient utility. The outside option $(j=0)$ includes off-label colon cancer treatments, regimens with small market shares, or regimens without a complete set of attributes. The utility of the outside options is set to zero.

Market shares for each regimen $j$ are defined as

$$
s_{j t}=\frac{\exp \left(-\alpha p_{j t}+\beta x_{j}+\xi_{t}+\Delta \xi_{j t}\right)}{1+\sum_{k=1}^{J_{t}} \exp \left(-\alpha p_{k t}+\beta x_{k}+\xi_{t}+\Delta \xi_{k t}\right)}
$$

This leads to the following demand equation

$$
\ln s_{j t}-\ln s_{0 t}=-\alpha p_{j t}+\beta x_{j}+\xi_{t}+\Delta \xi_{j t}
$$


Berry (1994) provides details of this derivation.

In this model all the individual-specific heterogeneity is contained in the idiosyncratic shock to preferences and, therefore, it suffers from the well-known independence of irrelevant alternatives criticism. ${ }^{16}$ Berry and Pakes (2007) propose an alternative demand model that removes the idiosyncratic shock from the indirect utility function and assign a random coefficient to at least one product attribute. In our pharmaceutical context, this pure characteristics model implies that physicians are perfect agents for their patients and are not affected by detailing or rebates. The pure characteristics model has a "local" substitution pattern, while the model with the idiosyncratic shock has a global pattern. ${ }^{17}$ However, based on numerical simulations similar to those in Section 5, we conclude that the vertical model (the one-random-coefficient-pure characteristics demand model) does not correctly characterize the market with cocktail regimens.

Thus, as an alternative model we divide regimens into groups and estimate a nested logit demand model. As mentioned in Section 2, the NCCA recommends 5FU/LV (the generic regimen), Roche's stand-alone regimen, and the Pfizer and Roche cocktail regimen for patients who cannot tolerate intensive therapy and other regimens for less frail patients. Following this recommendation, we form two regimen groups. In this model the degree of substitution within a group can differ from the degree of substitution across groups. ${ }^{18}$ Following Berry (1994), the nested logit demand equation is

$$
\ln s_{j t}-\ln s_{0 t}=-\alpha p_{j t}+\beta x_{j}+\sigma \ln s_{j / g}+\xi_{t}+\Delta \xi_{j t}
$$

where $\ln s_{j / g}$ is a regimen's within-group market share.

\section{$5 \quad$ Numerical Analysis}

Before we apply models to the data, we examine cross-firm bundling numerically in the simplest setting. In the benchmark case, firm 1 and firm 2 sell one stand-alone regimen each without cross-

\footnotetext{
${ }^{16}$ Although we could alleviate this problem by allowing for random coefficients on price and product attributes following Berry, Levinsohn, and Pakes (1995), we are unlikely to identify the random coefficients with our existing data set. Usually one needs the consumer distribution from multiple markets as in Nevo (2000), or micro choice data as in Petrin (2002). We, on the other hand, observe the same market over time and lack micro choice data on physicians' decisions.

${ }^{17}$ See Berry and Pakes (2007) and Song (2007) for a more detailed discussion of the differences between these two models.

${ }^{18}$ When we allow for more groups, the estimation results are similar, as described in section 6 .
} 
firm bundling (i.e., no cocktail regimen). The firms compete a la Bertrand and consumer demand is based on the utility function in equation (3). Assuming a price coefficient of -1 and given product quality, which we denote $\delta_{j}$ for $j=1$ and 2 , the firms set price to maximize static profits. ${ }^{19}$ In the empirical analysis we use actual market share data and observed regimen attributes to estimate product quality and fix its value, but in the numerical analysis we change quality to study how quality differentiation affects prices, profit, and consumer surplus.

We introduce a cocktail regimen by allowing the two firms to combine their drugs, given $\delta_{1}$ and $\delta_{2}$. We assume that this third regimen's product quality, say $\delta_{3}$, is the maximum of $\delta_{1}$ and $\delta_{2}$. The cocktail regimen can be produced using different combinations of the two drugs. Recall from Section 4 that $q_{r f}$ is the dosage of a drug produced by firm $f$ used in regimen $r$. For simplicity we set $q_{11}=q_{22}=1$ such that $p_{1}^{R}=p_{1}$ and $p_{2}^{R}=p_{2}$. For the cocktail regimen we let $r_{31}$ and $r_{32}$ be proportions of drugs 1 and 2 used in regimen 3 such that $r_{31}+r_{32}=1,0<r_{31}<1$, and $0<r_{32}<1$. The price of regimen 3 will be determined by

$$
p_{3}^{R}=r_{31} p_{1}+r_{32} p_{2}
$$

We also allow $r_{31}$ to vary in order to study its impact. The profit-maximizing first order condition is identical to equation (2) with $q_{11}=q_{22}=1$ and $q_{31}=r_{31}$. The marginal cost is assumed to be one-tenth of the stand-alone regimen's quality, i.e., $m c_{j}=\delta_{j} / 10$ for $j=1,2$.

In our first numerical analysis we set $r_{31}$ to be 0.5 and $\delta_{1}$ to be 1 , and allow $\delta_{2}$ to change from 1 to 3 so that the quality difference between regimens changes from 0 to 2 . A new equilibrium is computed for each value of $\delta_{2}$. This simple exercise allows us to understand how a firm's behavior changes as the difference in regimen quality increases. Figure 2 compares firms' profit between cases with the cocktail regimen versus the benchmark case (no cocktails). The $\mathrm{x}$-axis measures the quality difference between firm 2's stand-alone regimen and firm 1's stand-alone regimen, i.e., $\delta_{2}-\delta_{1}$, and the $\mathrm{y}$-axis measures profit. Figure 2 demonstrates that the presence of the cocktail regimen increases profit for both firms relative to not having a cocktail. Higher profit occurs as firms decide to charge higher prices with the presence of a cocktail regimen. This is similar to a

\footnotetext{
${ }^{19}$ Product quality is a linear function of observed and unobserved product attributes in equation (4), i.e. $\delta_{j}=$ $\beta x_{j}+\xi_{t}+\Delta \xi_{j t}$.
} 
case where a firm that produces multiple substitutes earns higher profit by charging higher prices. ${ }^{20}$ An interesting difference is that the cocktail regimen serves a multi-product function for both firms at the same time.

Figure 2 also shows that as the quality difference widens, profit increases faster for the lowversus the high-quality firm relative to the benchmark case with no cocktail regimen. This occurs because the low-quality firm "free-rides" on the relatively high quality provided by the cocktail regimen. In the benchmark case the low-quality firm decreases its price while the high-quality firm increases price as the quality difference widens. With the cocktail present, however, as the quality difference widens the low-quality firm increases its price to the point where the market share of its stand-alone regimen becomes negligible. But the low-quality firm still earns considerable profits from the cocktail regimen. The high-quality firm also increases its price, but not as substantially as the low-quality firm, so that it sells both its stand-alone regimen and the cocktail regimen.

Consumers experience offsetting effects. They benefit from having one more product available in the market but are hurt by the resulting higher prices. In our case the latter (negative) effect is larger than the former (positive), so consumers are worse off with the cocktail regimen, and further worse off as the quality difference increases. Compared to the benchmark case, consumer surplus is about 0.4 percent lower when $\delta_{2}-\delta_{1}=0$ and about 8.0 percent lower when $\delta_{2}-\delta_{1}=2$.

Whether consumer surplus falls, as it does in the above example, depends on how sensitive consumers are to price. If $\delta_{2}-\delta_{1}=0$, consumers are better off with the cocktail regimen when the price coefficient is smaller (more negative) than -1.7. Prices with cocktails increase less and consumers are hurt less when consumers are more price sensitive. Even with a moderate quality difference, however, consumers are hurt by the cocktail regimen for a wide range of values for the price coefficient. When the price coefficient is -2.5 , the lowest value that sustains both firms in the market in the benchmark case, consumers are worse off with the cocktail regimen when $\delta_{2}-\delta_{1}$ is larger than 0.2 .

We next ask whether the two firms can earn larger profits with a cocktail regimen or by merging without participating in a cocktail regimen. Figure 3, which compares firms' profits between the cocktail regimen case and the merger case, demonstrates that both firms earn larger profits with a cocktail regimen versus a merger. Firm 1's profit is about 20 percent higher when

\footnotetext{
${ }^{20}$ See Tirole (1998) p.70.
} 
$\delta_{2}-\delta_{1}=0$, and the profit difference (relative to a merger) grows as the quality gap widens. Firm 2's profit is also about 20 percent higher with the cocktail versus a merger when $\delta_{2}-\delta_{1}=0$, but the profit difference decreases as the quality gap widens.

The firms have higher demand for their products with the cocktail regimen, but they do not lower their prices to attract consumers. In fact, the firms charge higher prices with the cocktail regimen than in the merger case once the quality difference becomes sufficiently large. Specifically, firm 2 charges a higher price as soon as $\delta_{2}-\delta_{1}$ exceeds 0.05 , and firm 1 charges a higher price when $\delta_{2}-\delta_{1}$ exceeds 0.5 . Despite higher prices, consumer surplus is 29 to 36 percent higher with the cocktail regimen and no merger versus a merger without the cocktail regimen, due to the benefit of having another product available.

Interestingly, when we let the two firms merge while allowing them to keep the cocktail regimen, the merger provides small incremental benefits. The merging firm increases the prices only marginally, and the combined profit is less than one percent higher. This implies that firms almost fully internalize externalities with the cocktail regimen. As we elaborate in Section7.2, the small incremental benefits of merging occurs in part because the acquisition of a complementary product creates an incentive for the newly-merged firm to reduce prices. Thus, firms may not have a strong incentive to merge once they participate in a cocktail regimen, particularly if there are transactions costs associated with merging. Consumers are clearly worse off with the merger because the cocktail is available without the merger.

In the next numerical analysis we allow one of the two firms to set two separate prices: one for the stand-alone regimen and another for their drug in the cocktail regimen. This situation is equivalent to a case where a firm has two separate drugs, one used in a stand-alone regimen and the other used in a cocktail regimen. We first let firm 1, the low-quality firm, to set two separate prices while varying $\delta_{2}$ from 1 to 3 . Figure 4 compares the two prices that firm 1 now sets versus its single price from the first numerical analysis (Price1_Single). This figure demonstrates that the firm sets a much lower price for the stand-alone regimen (Price1_Solo) than for the cocktail regimen (Price1_Cocktail). Over the entire range of the quality difference, the former price is about a 50 percent lower than the latter.

Compared to the baseline single price (Price1_Single) case, the firm sets about a 14 percent lower price for the stand-alone regimen and a 66 percent higher price for the cocktail regimen when 
$\delta_{2}-\delta_{1}=0$. As the quality difference widens, the single price increases much faster than the other two prices. Recall that with the single price, firm 1 sacrifices its stand-alone regimen's market share as the quality gap increases and earns profit mostly from the cocktail regimen. Now with more flexible pricing, the market share of firm 1's stand-alone regimen is larger than that of the cocktail regimen, although it still free-rides on the cocktail regimen's high quality by curbing the price increase for its component of the cocktail regimen. (The unconstrained price is only 27 percent higher than the restricted price when $\delta_{2}-\delta_{1}=2$, as compared to 66 percent higher when $\left.\delta_{2}-\delta_{1}=0.\right)$

Not surprisingly, firm 1 is better off with the more flexible pricing, while firm 2 is worse off. Firm 2 now charges about 90 percent of what it used to charge. Firm 1's profit is about 6 percent higher than in the single pricing case, and profit does not change much as the quality gap widens. Firm 2's profit is about 12 percent lower in the flexible pricing case when $\delta_{2}-\delta_{1}=0$ and 9 percent lower when $\delta_{2}-\delta_{1}=2$. However, firm 2's profit is still higher than in the absence of the cocktail regimen (the benchmark case.)

We next let firm 2, the high quality firm, set two separate prices. Firm 2 also sets a much lower price for the stand-alone regime than for the cocktail regimen. However, both prices increase as the quality difference widens. This price increase seems to reduce the ability of firm 1 to freeriding on the cocktail regimen's high quality. As in the previous case, firm 2 is better off with the more flexible pricing while firm 1 is worse off.

Finally, we fix $\delta_{1}=1$ and $\delta_{2}=1$, and let $r_{31}$ change from 0.5 to 0.9 . This exercise helps us understand how the incentives to participate in making the cocktail regimen change when for chemical and/or biological reasons, one firm's drug constitutes a higher percentage of the cocktail recipe. We find, not surprisingly, that the profit for firm 1 increases as its mixture ratio increases, and the reverse is true for firm 2 as its mixture ratio decreases. Compared to the benchmark case, firm 1's profit is always higher and firm 2's profit is higher up to $r_{31}=0.8$ and then becomes lower beyond that point. We repeat this exercise by varying $r_{32}$ from 0.5 to 0.9 while fixing $\delta_{1}$ and $\delta_{2}$ and obtain qualitatively same results. 


\section{Demand Estimation}

We estimate equation (4) using regimen-level market share, price, and attribute data. The price variable is likely to be correlated with the unobserved attributes or contemporaneous demand shock because firms observe them before setting prices. This price endogeneity problem requires using instruments to consistently estimate the demand equation. We construct two instruments with the lagged prices of other regimens. In particular, for the price of regimen $j$ in period $t$, one instrument is the average price in period $t-1$ of all regimens other than regimen $j$, and the other is the average price in period $t-1$ of regimens produced by firms whose drugs are not used in regimen $j$.

Our identifying assumptions are that these instruments are uncorrelated with the currentperiod demand shock, but are correlated with the current period price of regimen $j$. The latter correlation should occur due to oligopolistic interactions and the evidence that the price of a given product is usually autocorrelated. The former assumption requires that a demand shock for regimen $j$ in period $t$ is uncorrelated with a demand shock for regimen $k$ in period $t-1$, and is likely to hold true. However, this condition could be violated if there exists a time-persistent market-level demand shock. ${ }^{21}$

We use the generalized method of moments with $\left(\mathbf{Z}^{\prime} \mathbf{Z}\right)^{-1}$ as the weighting matrix, where $\mathbf{Z}$ includes the instrumental variables, all the observed regimen attributes other than price and the time dummy variables. ${ }^{22}$ The estimates are presented in Table 2. The first column reports the results of the OLS logit model; the second column, labeled IV Logit, reports results using lagged prices as instruments; and the third column, labeled Nested Logit I, reports results of the nested logit with two regimen groups. The last column, labeled Nested Logit II, corresponds to the nested logit where regimens for patients who can tolerate intensive therapy are again divided into two groups (three regimen groups in total). In the two nested logit models we treat the within-group share variable as an endogenous variable. In all specifications we use the logarithm of price as a regressor.

Comparing the price coefficient from the first column with the other three reveals that there is a positive correlation between price and the demand shock, and the instrumental variables

\footnotetext{
${ }^{21}$ We do not use other products' attributes as instruments because they do not vary much over time due to infrequent product entry and exit. The first stage F-statistics on joint significance of these instruments is less than five, and the estimation results are not substantially different from the OLS logit results that we present.

${ }^{22}$ Our sample size is not large enough to use the optimal weighting matrix.
} 
mitigate this problem. The price coefficient changes from -0.690 without instruments (OLS Logit) to -2.150 in $I V$ Logit, and to -1.557 and -1.794 in two nested logit models. The price coefficient is significantly different from zero at the one-percent level in all models. The F-statistic from the first stage F-test for the joint significance of the instruments is over 10 in all three specifications using instruments for price. In the nested logit models, the coefficient for the within-group share variable is 0.403 and 0.421 for Nested Logit I and Nested Logit II respectively, and statistically significant. This indicates that regimens are closer substitutes within a group than between groups. ${ }^{23}$ Allowing for more nestings in Nested Logit II does not affect the results substantially.

The efficacy attribute coefficients are statistically significant in $I V$ Logit and the nested logit models, but only the response rate coefficient is positive. Because these three variables are correlated with one another, we evaluate preferences for a linear combination of the three efficacy variables. In the IV Logit model, the average willingness to pay for obtaining the mean efficacy from a 12 -week treatment is about $\$ 70,000$ in 2005 . The average cost for that treatment in the same year is about $\$ 18,000$. The average willingness to pay for the mean efficacy is slightly smaller (by less than $\$ 3,000$ ) in the nested logit models.

Among the side effect variables, only the neutropenia coefficient is both statistically significant and negative as expected. The estimate implies that the average willingness to pay to reduce a chance of having neutropenia by one percent is about $\$ 900$. The other side effect variables are either positive or insignificant. This may occur because cancer patients often take drugs that ameliorate the impact of certain side effects, such as pain, nausea, and diarrhea, while neutropenia is fatal and harder to prevent with other drugs. If a physician prescribes anti-pain and antiemetic drugs in conjunction with the chemotherapys drugs, she may downgrade the importance of these side effects when choosing a regimen. Another possible explanation is that the toxic drugs are more likely to cause side effects but have other favorable unmeasured attributes. Thus, it is important to include these variables because, if left in the unobserved attribute term, they are likely to be correlated with the efficacy variables. ${ }^{24}$

\footnotetext{
${ }^{23}$ The first stage F-statistics reported for the nested logit models in Table 2 is for the within-group share variable.

${ }^{24}$ Estmation results do not change substantially with different specifications. In Table A-1 we report estimates of alternative versions of the OLS and logit models, including versions without side effect variables and versions with manufacturer fixed effects.
} 


\section{Counterfactual Exercises}

With demand estimates we can recover the marginal cost of each drug using equation (1), and given the marginal cost and demand estimates we can compute hypothetical equilibrium prices under various counterfactual scenarios. We focus on the last six quarters of the sample period, i.e., from the second quarter of 2004 to the third quarter of 2005. That is a period in which all 12 major regimens are present in the market. All results are averaged over these six quarters. ${ }^{25}$ In this Section we present results using the estimates reported in the second column of Table 2 (IV Logit). Results using the estimates in the third column (Nested Logit I) are also presented in Tables A-2-A-4.

\subsection{Welfare Effects}

In the first counterfactual exercise we remove one cocktail regimen from the market at a time, calculate the new Nash equilibrium prices for all branded drugs, estimate profits for all major firms, and compute consumer surplus. This exercise is similar to the welfare counterfactual in Petrin (2002). Because there are six cocktail regimens, we evaluate six hypothetical cases. The results are reported in Table 3. The baseline reported in the first row, the situation actually observed in the market, is normalized to 100. Therefore, the table allows one to observe percentage changes in prices, profits, and consumer surplus when one particular cocktail regimen is removed compared to the observed situation. The numbers in bold typeface are level changes for firms that participate in the removed regimen (which we refer to as "participating firms" hereafter.) The rows are ordered from the oldest to the most recent cocktail that entered the market, and the columns are ordered from the earliest firm that sold a cocktail at the left to the most recent at the right.

The first panel of the table reports the estimated price of each firm's drug, relative to the baseline situation (100.0), when the particular regimen in a row is absent. For example, the final row corresponds to a scenario where the Sanofi-Genentech cocktail regimen, which had the highest market share of all regimens in 2005, is removed. Without this regimen, Sanofi and Genentech are predicted to decrease their drug prices by 45.3 percent and 12.2 percent, respectively.

\footnotetext{
${ }^{25}$ Since we solve a system of non-linear equations, there may be multiple sets of solutions. In most cases we do not encounter multiplicity with different starting points. In the few situations with multiplicity, we select the single equilibrium with the largest profits. See the following sections for more details.
} 
There are a few notable features of the first panel. In five out of six cases, prices of the participating firms' drugs are predicted to fall when a regimen is removed, which indicates that introducing a cocktail regimen is likely to increase participating firms' prices. Because price is a strategic complement, prices of drugs not used in the removed regimen generally fall as well. Roche is an exception; it consistently increases its price when other firms' cocktail regimens are removed. In all five of these cases, the price of the incumbent firm's drug in the cocktail (i.e., the first firm in bold typeface in a row) is predicted to fall by more than the price of the entering firm. This indicates that when a new cocktail regimen is introduced, the incumbent may be increasing price primarily to protect the market share of its stand-alone regimen.

The exceptions in the first panel, such as the predicted price increases in the second row and Roche's pricing reactions to other firms' cocktail regimen introductions, could result if the structure of cross-firm bundling is more complicated than we are able to model. When a cocktail regimen is removed in the numerical analysis, each firm was allowed a single stand-alone regimen. In the actual market, on the other hand, all drugs other than ImClone's are used in three cocktail regimens. When one cocktail regimen is removed, therefore, participating firms will still consider their other cocktail regimens when setting prices. ${ }^{26}$

The second panel of Table 3 reports estimated profit once a particular regimen is removed. No participating firm is better off without a regimen. Profit losses are sometimes substantial, especially when the cocktail's market share is much larger than that of a firm's stand-alone regimen. ImClone's profit (second to last row), for example, is predicted to fall by over 80 percent if its regimen, which has a market share three times larger than the market share of its stand-alone regimen, is removed. Non-participating firms are generally worse off too, although there are some exceptions, such as Roche in the Sanofi-Genentech case and ImClone in the Pfizer-Genentech case.

We report consumer surplus in the final column of Table 3. The effect of removing a regimen on consumer surplus is not clear a priori. Consumers are worse off with one fewer available product; but consumers benefit from the resulting lower prices. The demand model with an additive logit error term allows variety to provide the maximum possible benefit. Table 3 demonstrates that on net we predict that in five of the six cases consumers would be better off without the cocktail

\footnotetext{
${ }^{26}$ Roche's pricing reaction shows that price can become a strategic substitute when firms have a cocktail regimen in common.
} 
regimens. All drug prices are predicted to increase when the Pfizer-Roche cocktail is removed, so consumers clearly benefit with this cocktail. In general, consumer gains from the price decreases tend to outweigh the losses from reduced variety.

The evidence on prices, profits and consumer welfare in Table 3 indicates that these particular cross-firm bundlings create a less competitive market that harms consumers. Firms setting prices in the presence of cocktail regimens consider the demand for the cocktail regimen as well as the demand for their stand-alone regimens. In doing so, firms internalize part of the externalities they impose on their competitors, which results in a less competitive outcome. This result leads to our next question: if a cocktail regimen renders a market less competitive, how does a cocktail scenario compare to a merger or perfect collusion? We answer this question in the next counterfactual exercise.

\subsection{Merger Analysis}

Table 4 reports the joint profit of the merging firms and consumer surplus when different pairs of firms merge, where the two firms' joint profit under the current situation (of offering the cocktail regimen) is normalized to 100. For comparison, the joint profit from the first counterfactual exercise is reported in the second column, which is labeled Removed. The profit loss can be as large as 49 percent when the Sanofi-Genentech regimen is removed.

In the column labeled Removed+Merger we report the joint profit when the two firms merge without the cocktail regimen. Although the joint profit in third column exceeds that of the second because the two firms have more market power, this profit is not necessarily larger than the current profit with the cocktail regimen. In fact, in three of five cases the joint profit of the merger is smaller than the joint profit with the cocktail regimen; firms gain more from cocktail regimens than from mergers. ${ }^{27}$ The difference is quite substantial; mergers are estimated to increase joint profit by less than 15 percent in these three cases whereas cocktail regimens increase profit by at least 30 percent.

In the column labeled Merger in Table 4 we report the joint profit when two firms merge while maintaining their cocktail regimen. Interestingly, this joint profit is not much higher than the current joint profit. The largest increase (10.2 percent) occurs when Pfizer and Roche merge.

\footnotetext{
${ }^{27}$ There are five instead of six cases in this counterfactual exercise because we do not model a three-firm merger.
} 
Compared to the profit change from adding the cocktail regimen (column 1 - column 2), a merger increases the joint profit only marginally, confirming our finding in Section 5.

In our counterfactual exercise the merging firm does not always increase prices. In the Pfizer-Roche and the Roche-Sanofi mergers, the merging firm raises both drugs' prices as in the numerical simulation. In the Pfizer-Genentech merger, on the other hand, the merged firm reduces Genentech's drug price while raising Pfizer's drug price. More interestingly, in the last two merger cases the merging firm reduces both drugs' prices.

This mixed pricing result seems to be driven by a tension between complementary effects and market power effects. Without complementarity a merging firm always increases prices, but because it now has a complement, the merging firm has an incentive to reduce prices. ${ }^{28}$ Thus, the merging firm would not increase prices as much as it would without a complement and may decrease prices if the complementary effects dominate.

The mixed pricing result also indicates that the merging firm's joint profit is not always higher than the current joint profit. $^{29}$ If the merging firm reduces prices because of dominant complementary effects, the other firms' prices, which are strategic complements, may go down as well, which can hurt all firms including the merging firm. Although this does not occur in the last two merger cases in Table 4, in Table A-3 we show that a merger can lead to reduced profit when Pfizer and ImClone merge with their cocktail regimen and we model demand with a nested logit. In the scenario reported in Table A-3, the merging firm's joint profit is about two percent lower than the current joint profit. ${ }^{30}$

As expected, consumer surplus decreases when firms merge without the cocktail (going from Removed to Removed + Merger $)$ and increases when firms add the cocktail regimen while being merged (going from Removed + Merger to Merger), as displayed toward the right of Table 4 . In the former case consumer surplus falls as the market becomes less competitive; in the latter case consumer surplus rises as another product is added to the choice set. However, consumer surplus can change in either direction when two firms offering a cocktail regimen are allowed to merge

\footnotetext{
${ }^{28}$ This is basically the same as a double marginalization problem with a complement.

${ }^{29} \mathrm{~A}$ merger is not always profit enhancing in an oligopolistic setting. It is well known that in a symmetric three-firm Cournot environment, a merger between any two firms is not profit enhancing. This is because the third firm responds to a merger by increasing its quantity.

${ }^{30}$ Consider a simple case with linear demand where two price-setting firms independently sell perfect complements. A merger between the two is not necessarily profitable if there is a third firm selling a bundle of differentiated complements.
} 
(going from Current to Merger). Since the number of regimens does not change, it depends solely on how the firms change prices after a merger.

\subsection{Setting Two Prices}

In our third counterfactual exercise we allow one of the participating firms in a cocktail to set two separate prices for the same drug: one for its stand-alone regimen and one for its drug in the cocktail. This is the same exercise as the two-price setting case in Section 5. As mentioned, we use this exercise as a validation test for our static Nash pricing assumption. Moreover, this exercise sheds light on the welfare effects of Abbott's pricing strategy in the HIV/AIDS market.

Table 5 reports price, profit, and consumer surplus when firms have pricing flexibility, where the baseline levels are indexed to 100. The column labeled Solo reports the optimal drug prices for the stand-alone regimen and the numbers in bold typeface are prices for the drug used in the cocktail regimen. In the second row, for example, we predict that Pfizer would reduce the price of irinotecan by almost 60 percent for its stand-alone regimen while increasing the price of irinotecan by 25 percent for use in its three cocktail regimens.

Table 5 shows that the drug price for cocktail regimens can go up dramatically with additional price flexibility. Roche increases its drug price for cocktail regimens by a factor of five (in the fourth row) and Sanofi does so by almost two times (in the fifth row). Drug prices for the stand-alone regimens usually decrease substantially, ranging from 23.5 to 57.2 percent. A firm tries to attract consumers to its stand-alone regimen by charging a higher price for a drug used in cocktails. The market share of the cocktail regimen in question affects the magnitude of the price change. For example, ImClone changes prices moderately (the last row) because its cocktail regime has a much larger market share than its stand-alone regime. The other firms' reaction to the new price scheme is mixed. As one price rises and another decreases, some firms respond more strongly to the rising price and others to the decreasing price.

The second panel of the table demonstrates that firms earn higher profits by setting two prices in almost all cases, which is consistent with the numerical example. An exception is Sanofi, whose profit falls by five percent. This seems to be driven by a large price decrease by Pfizer and Roche (24.4 and 29.7 percent, respectively), which harms all firms. ${ }^{31}$ The flexible pricing hurts the

\footnotetext{
${ }^{31}$ In the nested logit model all firms are better off by this flexible pricing. See Table A-4.
} 
other firms, although the magnitude is usually relatively small. However, Table A-4 shows that this is not always true. When Roche sets two prices, ImClone and Genentech are better off as well. A difference is that in this case all other firms raise their prices.

We report consumer surplus in the last panel of Table 5. Since the regimen qualities do not change in this counterfactual, the only variable affecting consumer surplus is price. Consumers pay a lower price for some regimens and a higher price for others. Thus, the net effect is determined by the magnitude of price changes and regimens market shares. Consumer surplus is higher in all cases, but Table A-4 shows an exception where consumer surplus is lower when Roche sets two prices and we model demand with a nested logit. This is also a case where all firms increase prices.

These results demonstrate that it is hard to predict the welfare effects of the flexible pricing scheme. Firm profits and consumer surplus may change in either direction depending on how firms react to the flexible pricing. This suggests that Abbott's pricing strategy with Norvir and Kaletra is not necessarily detrimental to welfare. Nevertheless, the result that a firm lowers a price for a stand-alone regimen and raises a price for a drug used in cocktails is true in all models and specifications we investigate.

\section{Conclusions}

This paper is the first attempt to understand firms' decisions when their products are consumed in conjunction with their competitors' products. The firm controls only the price of its own product, and therefore needs to take into account the effect of its pricing strategy on all the bundles in which its product appears.

We apply our framework to the pharmaceutical industry, in particular to colorectal cancer chemotherapy drugs. We estimate regimen-level demand using unique data from IntrinsiQ, and perform a series of counterfactual exercises using estimates of the demand parameters and marginal cost. First, we find that inter-firm combinations are likely to enhance profit for all firms participating in a product combination because the effect of internalizing pricing externalities dominates the business-stealing effect. However, consumers are likely to be worse off with the combined products,

despite more variety, because they pay higher prices. In settings where consumers are less price elastic, bundling may increase consumer welfare. 
We also find that firms earn higher profits with product combinations than mergers. Even if firms that already have product combinations merge, the merger increases profits only marginally. Interestingly, consumers are not necessarily worse off because the merged firm may lower prices to fully internalize the pricing externalities. These results suggest that the anti-competitive merger effects would be smaller when the products of merging firms are already consumed together in the market, and should help the government evaluate the expected outcomes of the recent merger wave in the pharmaceutical market.

In addition, we find that if a firm is able to set two different prices, one for its standalone regimen and another for its component in a cocktail regimen - rather than a single price for both products, it would set a much higher price for the cocktail component than the stand-alone product. This result is consistent with what we observe in other sectors of the pharmaceutical industry, such as Abbott's pricing strategy with Norvir and Kaletra, and supports our static Nash pricing assumption. 


\section{References}

[1] Berry, Steven T. 1994. "Estimating Discrete Choice Models of Product Differentiation." RAND Journal of Economics, 25: 242-262.

[2] Berry, Steven T., James Levinsohn, and Ariel Pakes. 1995. "Automobile Prices in Market Equilibrium." Econometrica, 63(4): 841-890.

[3] Berry, Steven T. and Ariel Pakes. 2007. "The Pure Characteristics Demand Model." International Economic Review, 48: 1193-1225.

[4] Blume-Kohout, Margaret E., and Neeraj Sood. 2008. "The Impact of Medicare Part D on Pharmaceutical R\&D." NBER Working Papers 13857.

[5] Bresnahan, Timothy F., Scott Stern, and Manuel Trajtenberg. 1997. "Market segmentation and the sources of rents from innovation: personal computers in the late 1980s." RAND Journal of Economics: 28, 17-44.

[6] Carlton, Dennis W., and Michael Waldman. 2002. "The Strategic Use of Tying to Preserve and Create Market Power in Evolving Industries." Rand Journal of Economics, 33: 194-220.

[7] Carlton, Dennis W., Joshua S. Gans, and Michael Waldman. 2007. "Why Tie a Product Consumers Do Not Use?" NBER Working Paper 13339.

[8] Chen, Yongmin. 1997. "Equilibrium Product Bundling." Journal of Business, 70: 85-103.

[9] Duggan, Mark, and Fiona Scott Morton. 2006. "The Distortionary Effects of Government Procurement: Evidence from Medicaid Prescription Drug Purchasing." Quarterly Journal of Economics, 121: 1-30.

[10] Duggan, Mark, and Fiona Scott Morton. 2010. "The Effect of the Medicare Drug Benefit on Pharmaceutical Prices and Utilization.", American Economic Review, 100: 590-607.

[11] Frank, Richard G., and David S. Salkever. 1997. "Generic Entry and Pricing of Pharmaceuticals." Journal of Economics and Management Strategy, 6(1): 75-90.

[12] Grabowski, Henry G., and John M. Vernon. 1992. "Brand Loyalty, Entry, and Price Competition in Pharmaceuticals after the 1984 Hatch-Waxman Act." Journal of Law and Economics, 35: $331-350$.

[13] Jacobson, Mirielle, and Joseph P. Newhouse. 2006. "Does Reimbursement Influence Chemotherapy Treatment for Cancer Patients?" Health Affairs, 25: 437-461.

[14] Ketcham, Jonathan, and Kosali Simon. 2008. "Medicare Part D's Effects on Eldely Drug Costs and Utilization." American Journal of Managed Care, November: 14-22.

[15] Lakdawalla, Darius, and Wesley Yin. 2010. "Insurers' Negotiating Leverage and the External Effects of Medicare Part D." NBER Working Paper 16251.

[16] Lichtenberg, Frank R., and S. X. Sun. 2007. "The Impact of Medicare Part D on Prescription Drug Use by the Elderly." Health Affairs, 26(6): 1735-1744.

[17] Lucarelli, Claudio, and Sean Nicholson. 2008. "A Quality-Adjusted Price Index for Colon Cancer Drugs." NBER Working Paper 15174. 
[18] Lucarelli, Claudio, Sean Nicholson, and Robert J. Town. 2010. "The Effect of Physician Reimbursement on Chemotherapy Treatment Decisions and Patient Outcomes." Unpublished.

[19] McAfee, R. Preston, and Michael D. Whinston. 1989. "Multiproduct Monopoly, Commodity Bundling, and Correlation of Values." Quarterly Journal of Economics, 104: 371-383.

[20] McFadden, Daniel. 1981. "Econometric Models of Probabilistic Choice." In Structural Analysis of Discrete Data with Econometric Applications, ed. Charles F. Manski and Daniel McFadden, 198-272. Cambridge, MA: The MIT Press.

[21] Nalebuff, Barry J. 2004. "Bundling As an Entry Barrier." Quarterly Journal of Economics, 119: $159-187$.

[22] Nevo, Aviv. 2000. "Mergers with Differentiated Products: The Case of the Ready-to-Eat Cereal Industry." RAND Journal of Economics, 31: 395-421.

[23] Petrin, Amil. 2002. "Quantifying the Benefits of New Products: The Case of the Minivan." Journal of Political Economy, 110: 705-729.

[24] Saha, Atanu, Henry Grabowski, Howard Birnbaum, Paul Greenberg, and Oded Bizan. 2006. "Generic Competition in the US Pharmaceutical Market." International Journal of the Economics of Business, 13(1): 15-38.

[25] Scott Morton, Fiona. 1999. "Entry decisions in the generic pharmaceutical industry." RAND Journal of Economics, 30: 421-440.

[26] Song, Minjae. 2007. "Measuring Consumer Welfare in the CPU Market: An Application of the Pure Characteristics Demand Model." RAND Journal of Economics, 38: 429-446.

[27] Tirole, Jean. 1998. The Theory of Industrial Organization. Cambridge, MA: MIT Press.

[28] Town, Robert J. 2001. "The Effects of HMO Mergers." Journal of Health Economics, 20: 733-753.

[29] Whinston, Michael D. 1990. "Tying, Foreclosure, and Exclusion." American Economic Review, 80: 837-859.

[30] Yin, Wesley, James Zhang, Shawn Sun, and Caleb Alexander. 2008. "Impact of the Medicare Part D Drug Benefit on Use of Generic Drugs and Different Therapeutic Drug Classes." Journal of General Internal Medicine, 23(10): 1673-1678. 


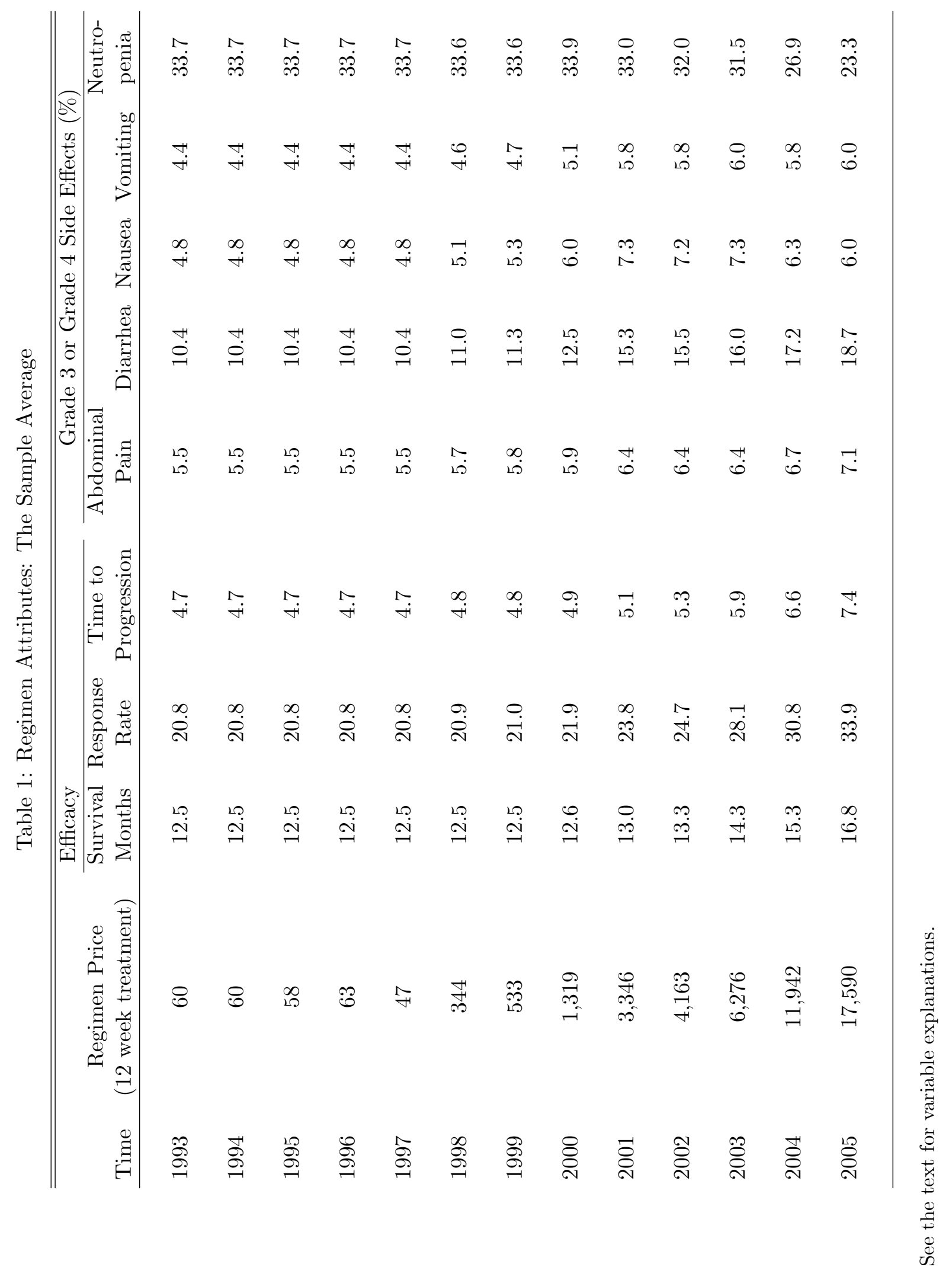


Table 2: Demand Estimation Results

\begin{tabular}{|c|c|c|c|c|}
\hline Variable & OLS Logit & IV Logit & Nested Logit I & Nested Logit II \\
\hline $\log ($ price $)$ & $\begin{array}{l}-0.690^{*} \\
(0.125)\end{array}$ & $\begin{array}{l}-2.150^{*} \\
(0.483)\end{array}$ & $\begin{array}{l}-1.557^{*} \\
(0.411)\end{array}$ & $\begin{array}{l}-1.794^{*} \\
(0.412)\end{array}$ \\
\hline Survival (months) & $\begin{array}{l}-0.087 \\
(0.056)\end{array}$ & $\begin{array}{l}-0.421^{*} \\
(0.116)\end{array}$ & $\begin{array}{l}-0.323^{*} \\
(0.093)\end{array}$ & $\begin{array}{l}-0.356^{*} \\
(0.097)\end{array}$ \\
\hline Response Rate (\%) & $\begin{array}{l}0.166^{*} \\
(0.072)\end{array}$ & $\begin{array}{l}0.913^{*} \\
(0.254)\end{array}$ & $\begin{array}{l}0.644^{*} \\
(0.214)\end{array}$ & $\begin{array}{l}0.784^{*} \\
(0.215)\end{array}$ \\
\hline $\begin{array}{c}\text { Time to Progression } \\
\text { (months) }\end{array}$ & $\begin{array}{l}-0.335 \\
(0.244)\end{array}$ & $\begin{array}{l}-2.070^{*} \\
(0.644)\end{array}$ & $\begin{array}{l}-1.395^{*} \\
(0.538)\end{array}$ & $\begin{array}{l}-1.830^{*} \\
(0.545)\end{array}$ \\
\hline Diarrhea & $\begin{array}{c}0.024 \\
(0.023)\end{array}$ & $\begin{array}{l}0.072^{*} \\
(0.034)\end{array}$ & $\begin{array}{c}0.051^{*} \\
(0.026)\end{array}$ & $\begin{array}{c}0.052 \\
(0.030)\end{array}$ \\
\hline Nausea & $\begin{array}{l}-0.137 \\
(0.078)\end{array}$ & $\begin{array}{l}-0.065 \\
(0.116)\end{array}$ & $\begin{array}{l}-0.059 \\
(0.082)\end{array}$ & $\begin{array}{l}-0.017 \\
(0.090)\end{array}$ \\
\hline Abdom_pain & $\begin{array}{c}0.135 \\
(0.077)\end{array}$ & $\begin{array}{l}0.806^{*} \\
(0.229)\end{array}$ & $\begin{array}{c}0.561^{*} \\
(0.196)\end{array}$ & $\begin{array}{c}0.681^{*} \\
(0.193)\end{array}$ \\
\hline Vomiting & $\begin{array}{c}0.166 \\
(0.118)\end{array}$ & $\begin{array}{c}0.245 \\
(0.166)\end{array}$ & $\begin{array}{c}0.196 \\
(0.116)\end{array}$ & $\begin{array}{c}0.176 \\
(0.134)\end{array}$ \\
\hline Neutropenia & $\begin{array}{l}-0.008 \\
(0.011)\end{array}$ & $\begin{array}{l}-0.109^{*} \\
(0.034)\end{array}$ & $\begin{array}{l}-0.082^{*} \\
(0.027)\end{array}$ & $\begin{array}{l}-0.098^{*} \\
(0.028)\end{array}$ \\
\hline $\log \left(s_{j / g}\right)$ & & & $\begin{array}{l}0.403^{*} \\
(0.154)\end{array}$ & $\begin{array}{l}0.421^{*} \\
(0.166)\end{array}$ \\
\hline R-square & 0.836 & & & \\
\hline $\begin{array}{c}\text { 1st Stage } \\
\text { F-statistics }\end{array}$ & & 11.983 & 27.235 & 20.960 \\
\hline
\end{tabular}




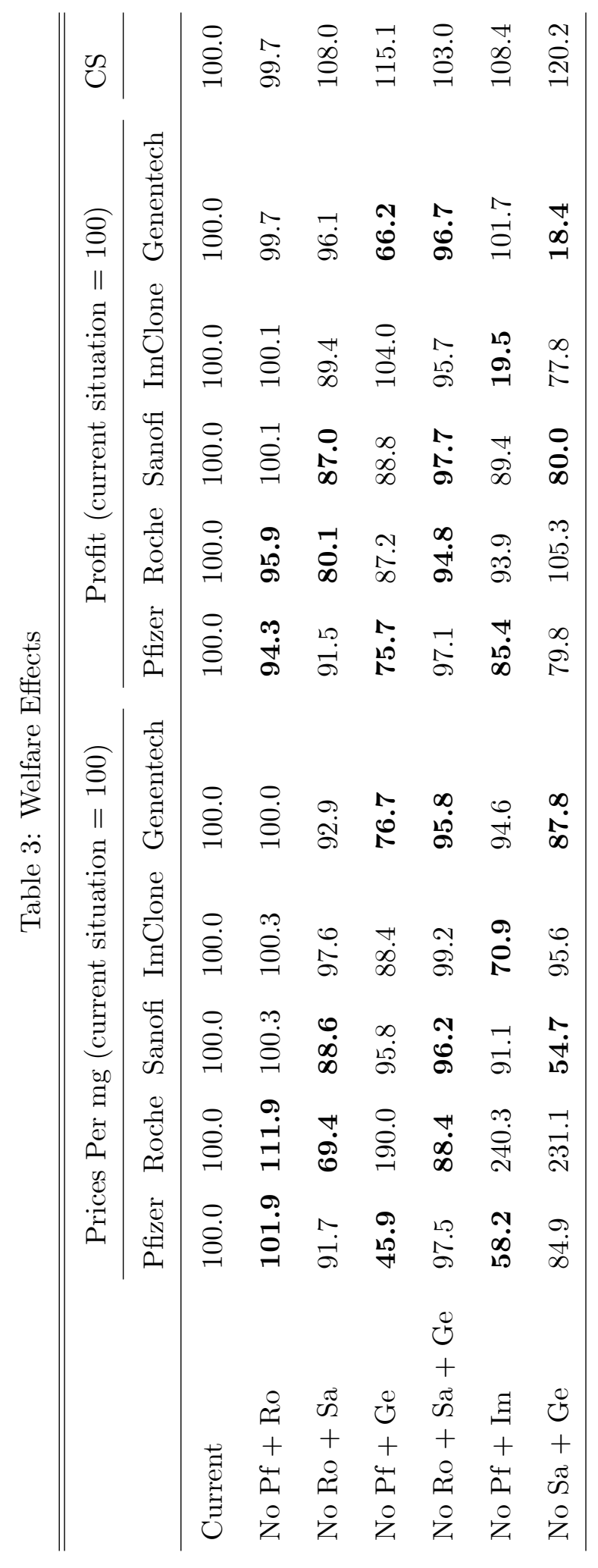




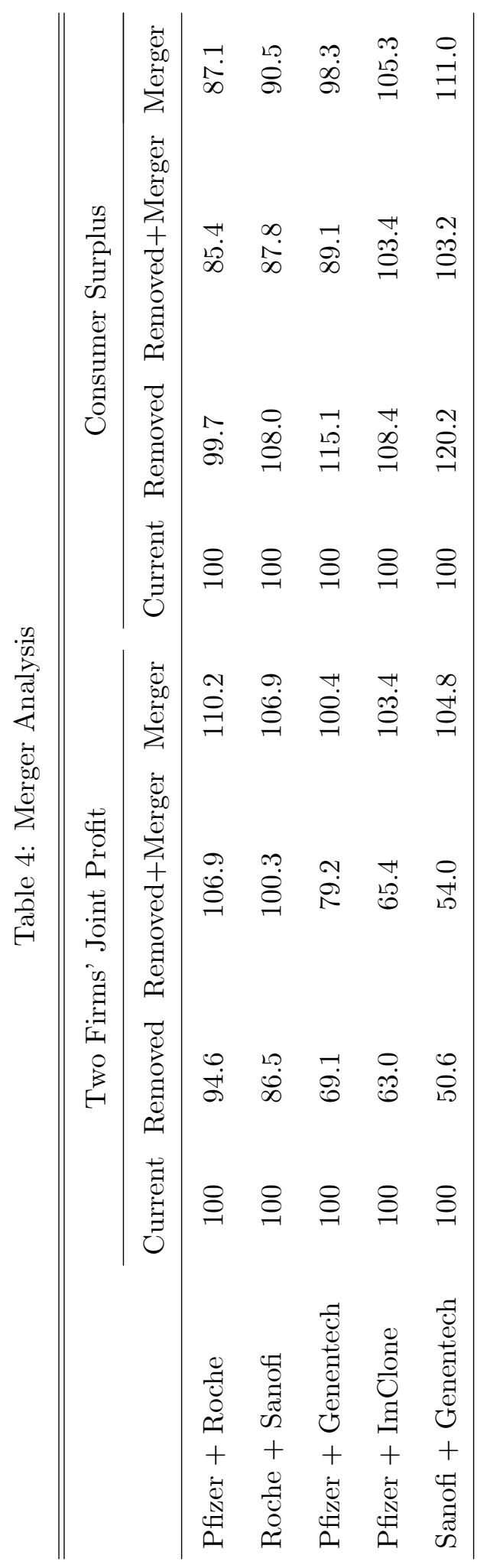




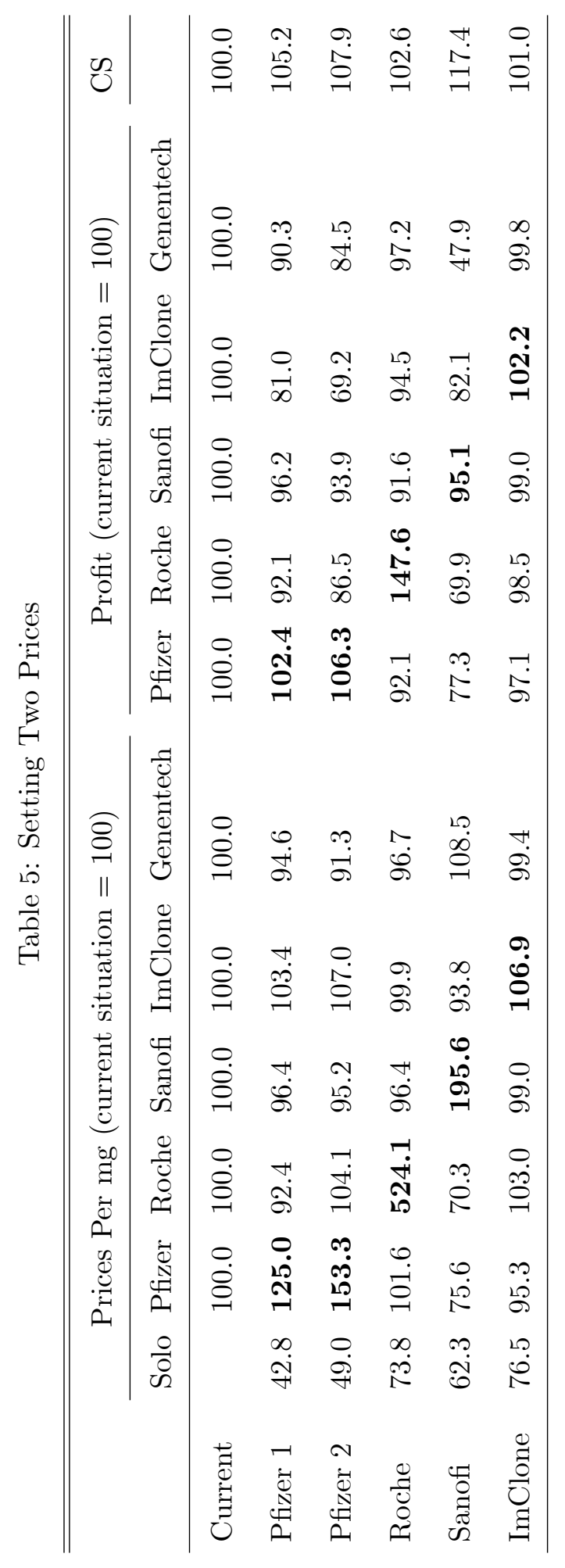




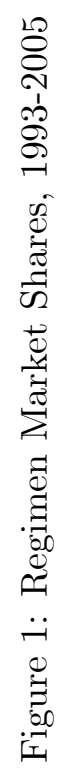

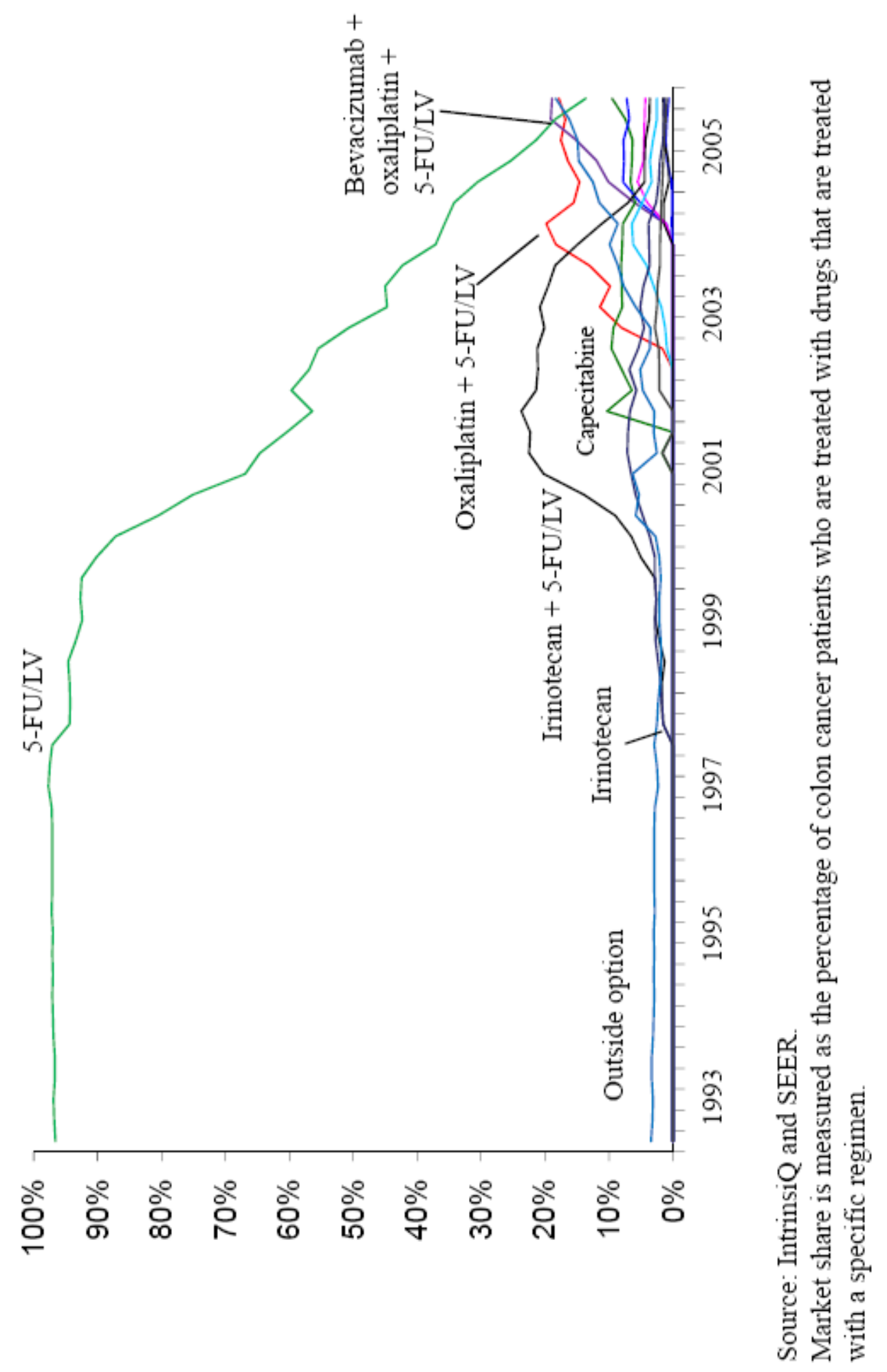




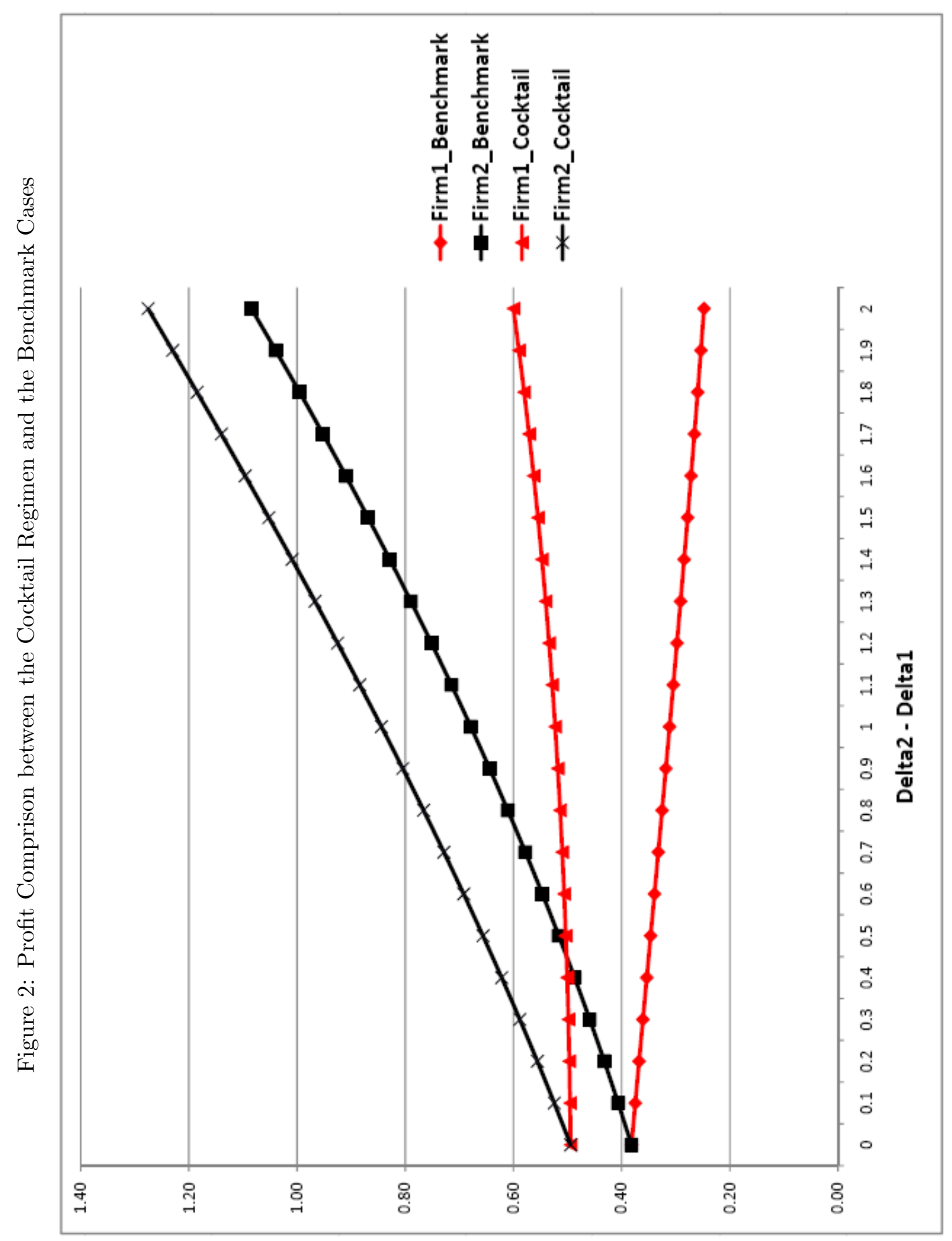




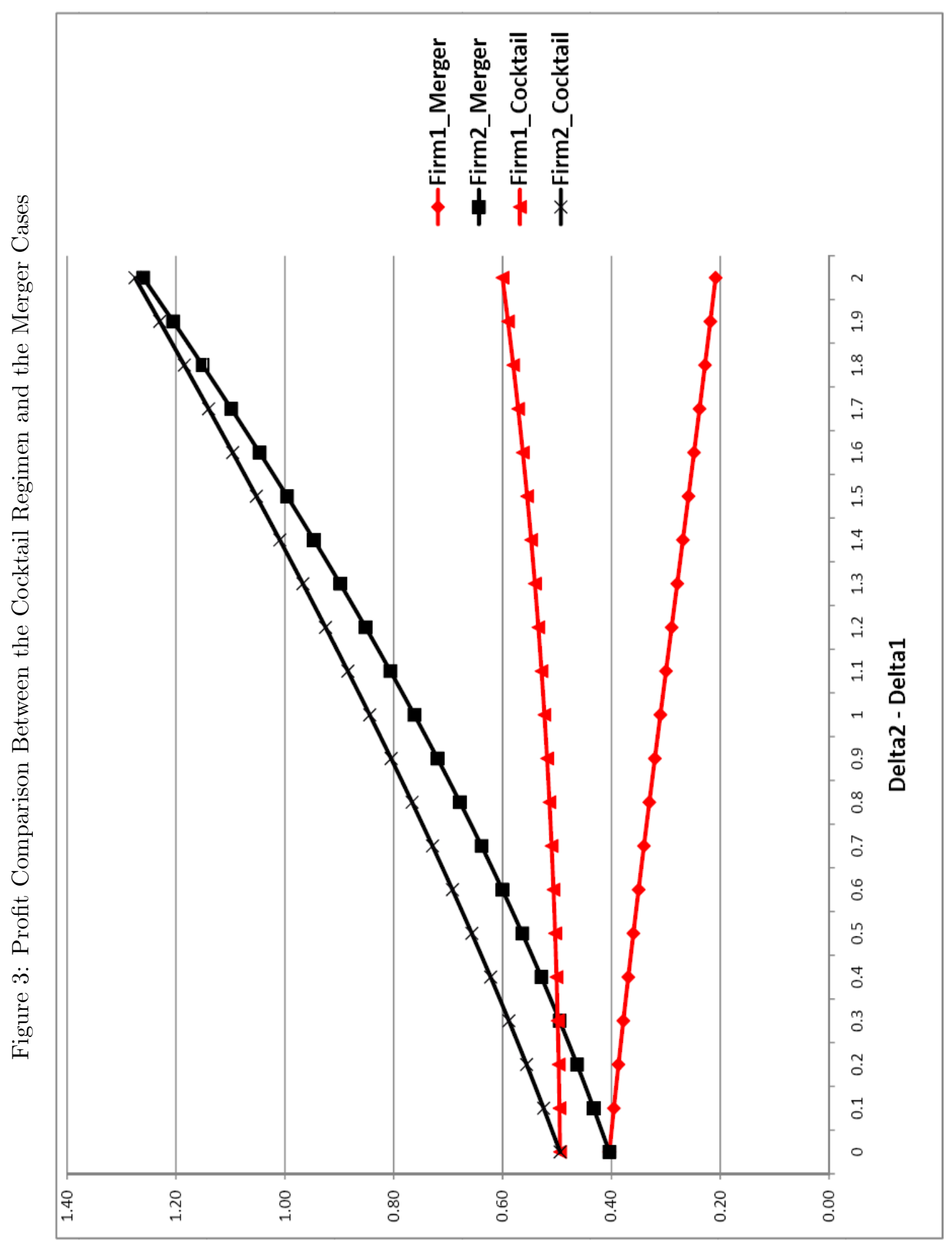




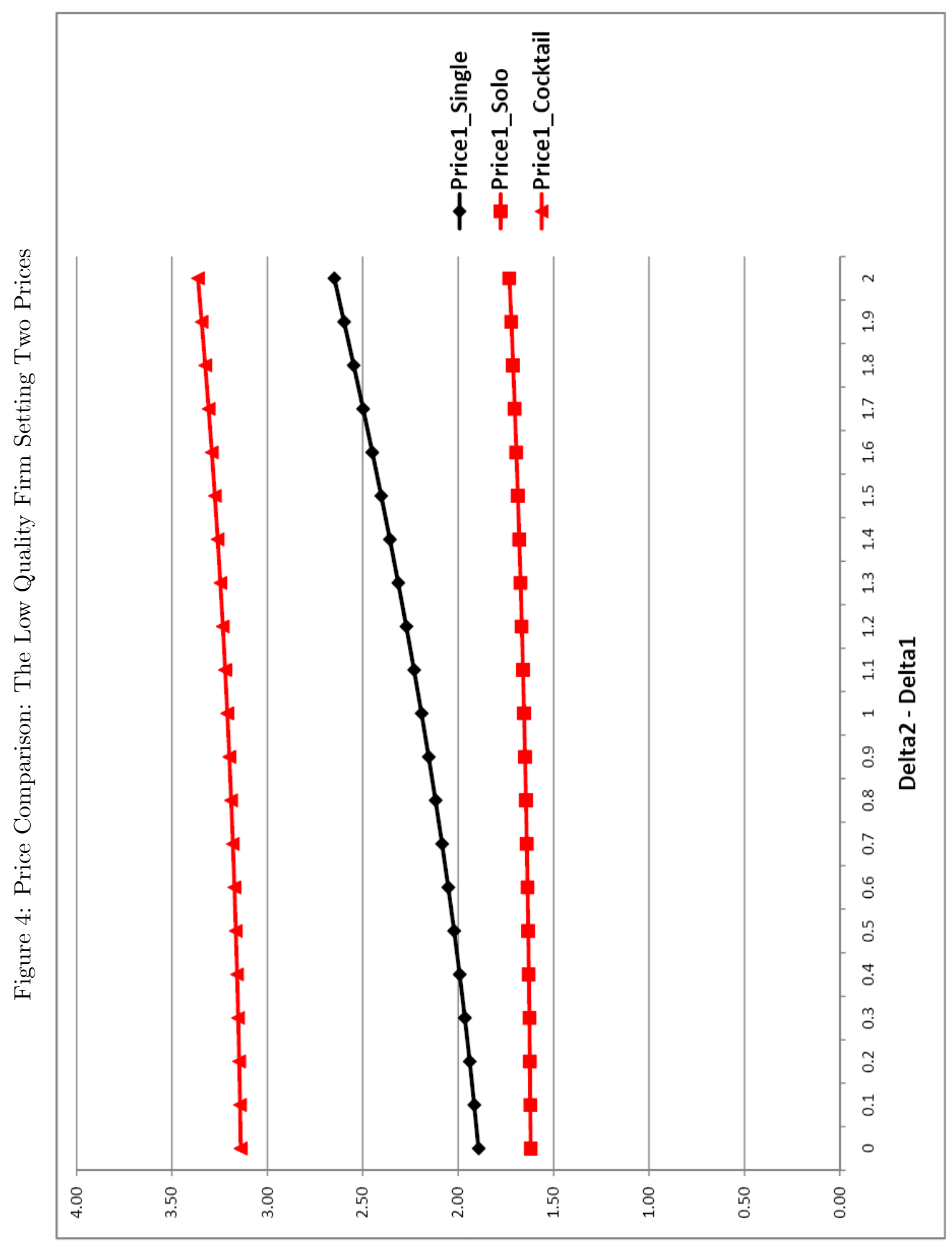


Table A-1: Demand Estimation with Various Specifications in the Logit Demand Model

\begin{tabular}{|c|c|c|c|c|c|c|c|c|}
\hline \multirow[b]{2}{*}{ Variable } & \multicolumn{2}{|c|}{ Specification 1} & \multicolumn{2}{|c|}{ Specification 2} & \multicolumn{2}{|c|}{ Specification 3} & \multicolumn{2}{|c|}{ Specification 4} \\
\hline & OLS & IV & OLS & IV & OLS & IV & OLS & IV \\
\hline $\log ($ price $)$ & $\begin{array}{l}-0.473^{*} \\
(0.039)\end{array}$ & $\begin{array}{l}-0.690^{*} \\
(0.064)\end{array}$ & $\begin{array}{l}-0.281^{*} \\
(0.060)\end{array}$ & $\begin{array}{l}-1.210^{*} \\
(0.302)\end{array}$ & $\begin{array}{l}-0.493^{*} \\
(0.051)\end{array}$ & $\begin{array}{l}-1.290^{*} \\
(0.218)\end{array}$ & $\begin{array}{l}-0.392^{*} \\
(0.060)\end{array}$ & $\begin{array}{l}-1.606^{*} \\
(0.437)\end{array}$ \\
\hline $\begin{array}{l}\text { Response } \\
\text { Rate (\%) }\end{array}$ & $\begin{array}{l}0.025^{*} \\
(0.008)\end{array}$ & $\begin{array}{l}0.043^{*} \\
(0.008)\end{array}$ & & & $\begin{array}{l}0.043^{*} \\
(0.009)\end{array}$ & $\begin{array}{l}0.128^{*} \\
(0.027)\end{array}$ & $\begin{array}{l}0.074^{*} \\
(0.010)\end{array}$ & $\begin{array}{c}0.118^{*} \\
(0.022)\end{array}$ \\
\hline Neutropenia & $\begin{array}{c}0.001 \\
(0.006)\end{array}$ & $\begin{array}{c}-0.011^{*} \\
(0.006)\end{array}$ & & & $\begin{array}{c}-0.022^{*} \\
(0.008)\end{array}$ & $\begin{array}{c}-0.111^{*} \\
(0.026)\end{array}$ & $\begin{array}{c}-0.045^{*} \\
(0.009)\end{array}$ & $\begin{array}{c}-0.131^{*} \\
(0.035)\end{array}$ \\
\hline Pfizer & & & $\begin{array}{c}-0.695^{*} \\
(0.266)\end{array}$ & $\begin{array}{l}2.730^{*} \\
(1.213)\end{array}$ & $\begin{array}{l}-0.027 \\
(0.205)\end{array}$ & $\begin{array}{l}2.439^{*} \\
(0.743)\end{array}$ & $\begin{array}{l}-0.515 \\
(0.276)\end{array}$ & $\begin{array}{l}4.293^{*} \\
(1.827)\end{array}$ \\
\hline Roche & & & $\begin{array}{c}-1.315^{*} \\
(0.174)\end{array}$ & $\begin{array}{l}-0.063 \\
(0.485)\end{array}$ & $\begin{array}{c}-1.314^{*} \\
(0.161)\end{array}$ & $\begin{array}{c}-1.621^{*} \\
(0.219)\end{array}$ & $\begin{array}{c}-1.892^{*} \\
(0.178)\end{array}$ & $\begin{array}{c}-1.577^{*} \\
(0.233)\end{array}$ \\
\hline ImClone & & & $\begin{array}{c}-0.988^{*} \\
(0.333)\end{array}$ & $\begin{array}{l}2.029^{*} \\
(1.095)\end{array}$ & & & $\begin{array}{l}-1.252^{*} \\
(0.304)\end{array}$ & $\begin{array}{c}0.646 \\
(0.935)\end{array}$ \\
\hline Sanofi & & & $\begin{array}{l}-0.125 \\
(0.298)\end{array}$ & $\begin{array}{l}3.244^{*} \\
(1.236)\end{array}$ & & & $\begin{array}{c}-0.948^{*} \\
(0.300)\end{array}$ & $\begin{array}{c}2.752 \\
(1.463)\end{array}$ \\
\hline Genentech & & & $\begin{array}{l}-0.332 \\
(0.241)\end{array}$ & $\begin{array}{c}0.553 \\
(0.504)\end{array}$ & & & $\begin{array}{l}-1.255^{*} \\
(0.246)\end{array}$ & $\begin{array}{c}-1.439^{*} \\
(0.440)\end{array}$ \\
\hline R-square & 0.819 & & 0.862 & & 0.875 & & 0.899 & \\
\hline $\begin{array}{c}\text { 1st Stage } \\
\text { F-statistics }\end{array}$ & & 80.204 & & 8.231 & & 14.828 & & 5.782 \\
\hline
\end{tabular}




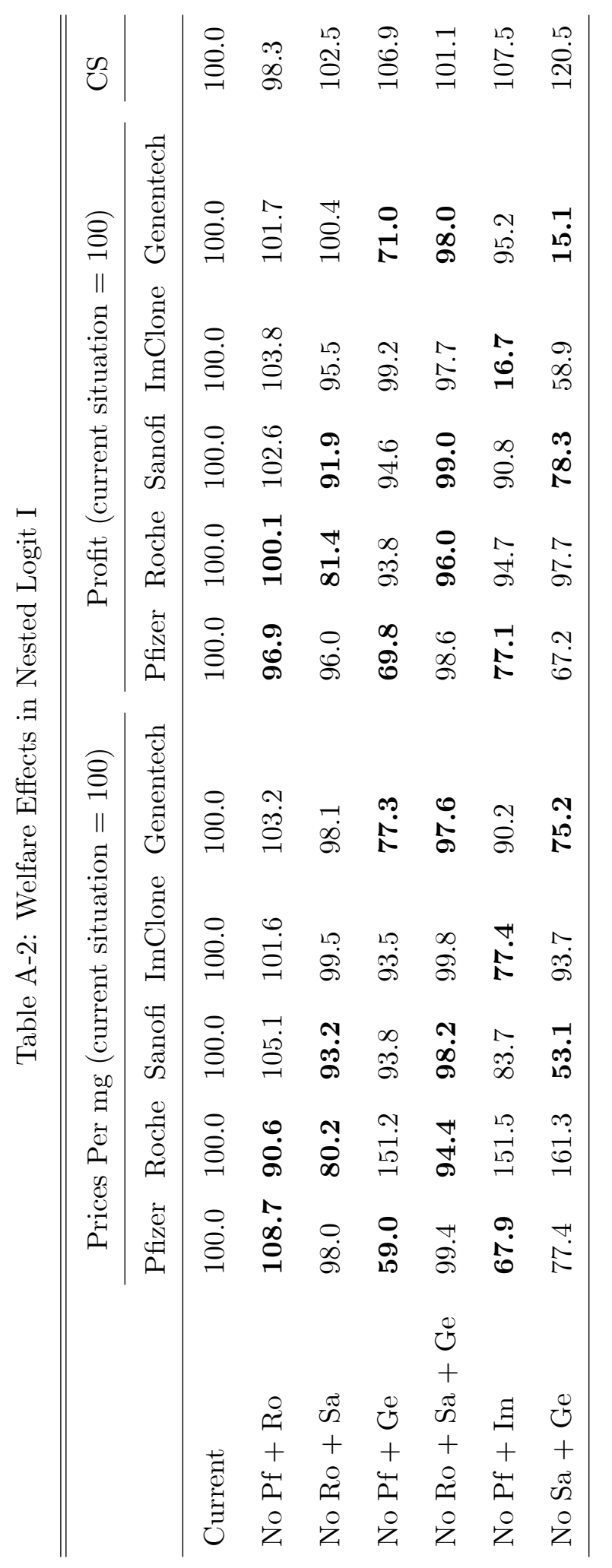




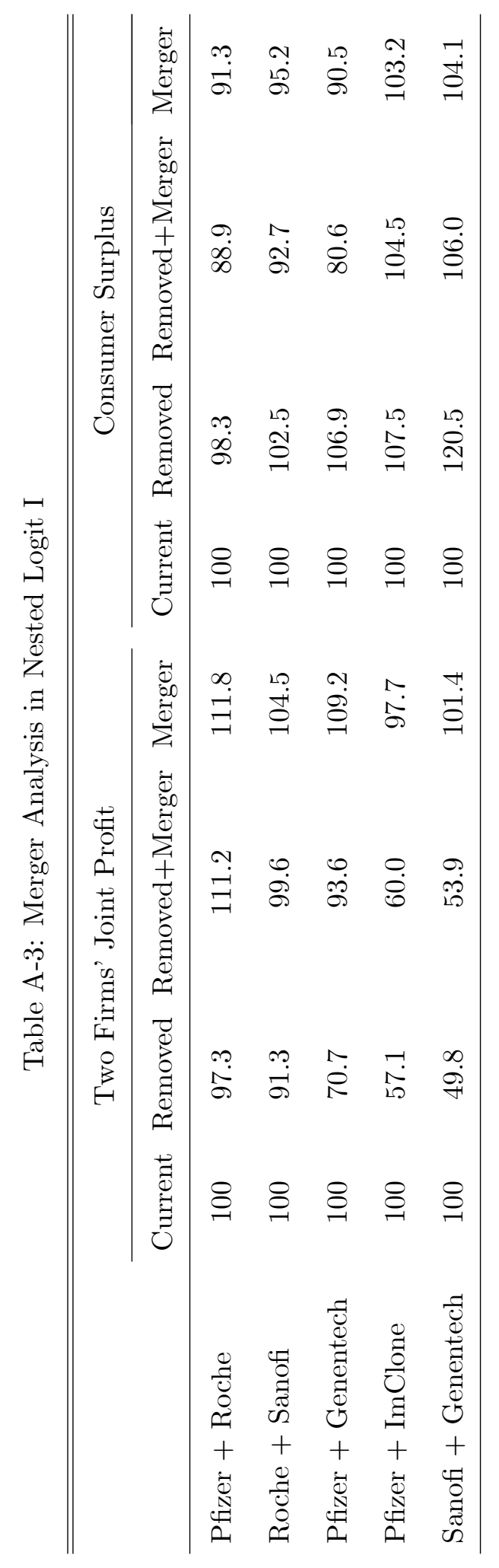




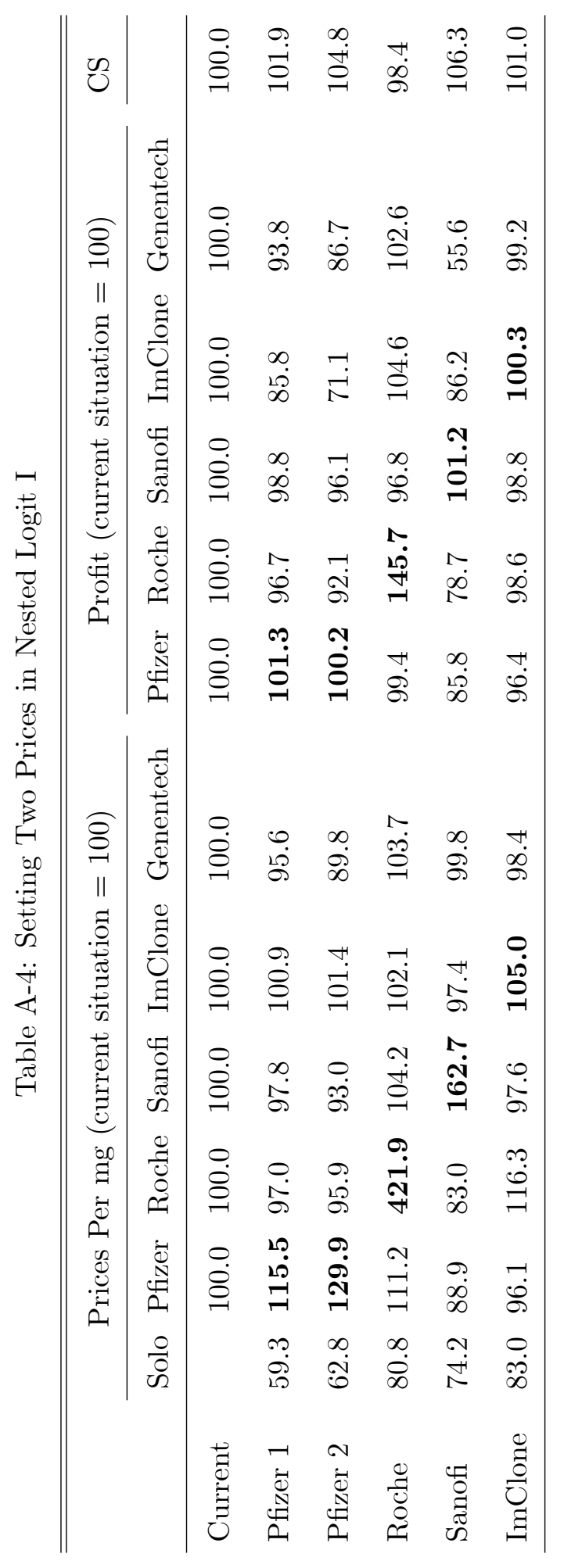

